\title{
Reversible coordinative binding and separation of sulphur dioxide in a robust metal-organic framework with open copper sites
}

Gemma L. Smith, ${ }^{1, a}$ Jennifer E. Eyley, ${ }^{1, a}$ Xue Han, ${ }^{1}$ Xinran Zhang ${ }^{1}$, Jiangnan Li, ${ }^{1}$ Nicholas M. Jacques, ${ }^{1}$ Harry G.W. Godfrey, ${ }^{1}$ Stephen P. Argent,${ }^{2}$ Laura J. M Cormick, ${ }^{3}$ Simon J. Teat,${ }^{3}$ Yongqiang Cheng ${ }^{4}$ Mark D. Frogley, ${ }^{5}$ Gianfelice Cinque, ${ }^{5}$ Sarah J. Day, ${ }^{5}$ Chiu C. Tang, ${ }^{5}$ Timothy L. Easun, ${ }^{6}$ Svemir Rudić, ${ }^{7}$ Anibal J. Ramirez-Cuesta, ${ }^{4}$ Sihai Yang ${ }^{1 *}$ and Martin $\operatorname{Schröder}^{1 *}$

1. School of Chemistry, University of Manchester, Manchester, M13 9PL (UK)

2. Department of Chemistry, University of Warwick, CV4 7AL (UK)

3. Advanced Light Source, Lawrence Berkeley National Laboratory, Berkeley, California 94720 (USA)

4. Oak Ridge National Laboratory, Oak Ridge, TN 37831(USA)

5. Diamond Light Source, Harwell Science Campus, Oxfordshire, OX11 0DE (UK)

6. School of Chemistry, Cardiff University, Cardiff, CF10 3AT (UK)

7. ISIS Facility, STFC Rutherford Appleton Laboratory, Chilton, Oxfordshire, OX11 0QX (UK)

a. these authors contributed equally to this work. 
Emissions of sulphur dioxide $\left(\mathrm{SO}_{2}\right)$ from flue gas and marine transport have detrimental impacts on the environment and human health, but $\mathrm{SO}_{2}$ is also an important industry feedstock if it can be recovered, stored and transported efficiently. Here we report the exceptional adsorption and separation of $\mathrm{SO}_{2}$ in a new porous material, $\left[\mathrm{Cu}_{2}(\mathrm{~L})\right]\left(\mathrm{H}_{4} \mathrm{~L}=4^{\prime}, 4^{\prime \prime \prime}\right.$-(pyridine-3,5-diyl)bis([1,1'biphenyl]-3,5-dicarboxylic acid), MFM-170. MFM-170 exhibits fully reversible $\mathrm{SO}_{2}$ uptake of 17.5 mmol $\mathrm{g}^{-1}$ at $298 \mathrm{~K}, 1.0 \mathrm{bar}$, and the $\mathrm{SO}_{2}$ binding domains for trapped molecules within MFM-170 have been determined. Significantly, we report the first example of reversible co-ordination of $\mathrm{SO}_{2}$ to open $\mathrm{Cu}(\mathrm{II})$ sites in a porous material, contributing to excellent adsorption thermodynamics and selectivities for $\mathrm{SO}_{2}$ binding, as well as facile regeneration of MFM-170 post adsorption. MFM-170 is stable to water, acid and base and shows significant promise for the dynamic separation of $\mathrm{SO}_{2}$ from simulated flue gas mixtures, as confirmed by breakthrough experiments.

The use of fossil fuels is a major contributer to many serious environmental issues, but transition to clean energy sources remains challenging as new technologies take time to fully develop. A significant problem is the release of $\mathrm{SO}_{2}$, for which antrophogenic sources account for $>87 \%$ of global emissions. ${ }^{1} \mathrm{SO}_{2}$ has detrimental effects on the environment and human health, but is also an important feedstock for the production of sulphuric acid. Furthermore, trace amounts of $\mathrm{SO}_{2}$ can greatly reduce the activity of aminebased scrubbers for $\mathrm{CO}_{2}$ from flue gas, ${ }^{2}$ as well as irreversibly poisoning catalysts for selective $\mathrm{NO}_{\mathrm{x}}$ reduction ${ }^{3}$ and $\mathrm{CH}_{4}$ combustion. ${ }^{4}$

In recent years, there has been growing interest in the development of dry regenerable sorbents for $\mathrm{SO}_{2}$ operating under ambient conditions. ${ }^{5-7}$ These materials offer advantages over existing wet flue gas desulphurisation (FDG) technologies by reducing energy and water requirements and minimising the generation of solid and liquid waste. Importantly, regeneration of sorbents allows recovery of saleable $\mathrm{SO}_{2}$, which can be utilised further via conversion to elemental sulphur or sulfuric acid. Regenerable $\mathrm{SO}_{2}$ sorbents are often used for scrubbing of sulphur by absorption of acid plant tail gases, as well as smelter off-gases (containing up to $8 \% \mathrm{SO}_{2}$ ), allowing the recovered $\mathrm{SO}_{2}$ to be cycled to the front end of the plant. ${ }^{8}$ These processes are typically based on alkaline solutions, which require high temperatures and/or further reaction for regeneration. Desirable properties of solid sorbents operating via pressure swing adsorption (PSA) mechanisms include: (i) high $\mathrm{SO}_{2}$ capacity, (ii) rapid sorption rate, (iii) low attrition rate (no loss of $\mathrm{SO}_{2}$ capacity over many cycles), (iv) ease of regeneration, and (v) high selectivity. High capacity sorbents for $\mathrm{SO}_{2}$ can also be used for safe transportation of recovered gaseous $\mathrm{SO}_{2}$ under ambient conditions, without the large energy demands required for pressurisation to liquid $\mathrm{SO}_{2}$ or reduction to solid elemental sulphur.

Porous metal-organic frameworks (MOFs) are emerging sorbents that have been studied extensively for uptake and separation of a wide variety of gases, notably $\mathrm{CO}_{2}, \mathrm{H}_{2}$ and hydrocarbons, ${ }^{9-14}$ but their application to $\mathrm{SO}_{2}$ capture has been hindered by the toxic and highly corrosive nature of this substrate. To date, several MOFs have been tested as $\mathrm{SO}_{2}$ adsorbents (Table 1, Fig 2), ${ }^{15-25}$ but many exhibit limited stability and/or reversibility under near-ambient conditions. Current top-performing $\mathrm{MOFs}$ for $\mathrm{SO}_{2}$ 
adsorption at $298 \mathrm{~K}$ and 1.0 bar include MFM-202a (10.2 $\left.\mathrm{mmol} \mathrm{g}^{-1}\right)^{18}$ and SIFSIX-1-Cu (11.0 $\left.\mathrm{mmol} \mathrm{g}^{-1}\right)^{16}$. The former is subject to an irreversible phase change on $\mathrm{SO}_{2}$ uptake, whilst the steep uptake of the latter may render it unfeasible for practical PSA applications. ${ }^{26,27}$ Indeed, a trade-off often exists between the uptake at low-pressure and the energy cost of system regeneration. Another consideration is that sorbents for use in FGD processes must be located upstream of $\mathrm{CO}_{2}$ scrubbing units, and therefore require high selectivity for $\mathrm{SO}_{2}$ over $\mathrm{CO}_{2}$ at low partial pressures of $\mathrm{SO}_{2}(\sim 2000 \mathrm{ppm})$. Although open metal sites in MOFs can improve gas binding selectivity, the resultant MOFs are often subject to severe framework degradation upon contact with water, precluding their practical applications. ${ }^{28-31}$ Similarly, coordination of strongly complexing $\mathrm{SO}_{2}$ molecules to open metal centres can disrupt the linker-metal coordination and cause structural collapse.

Herein, we report the first example of reversible coordinative binding of $\mathrm{SO}_{2}$ to open $\mathrm{Cu}(\mathrm{II})$ sites in a remarkably robust material, MFM-170, leading to optimal adsorption and selectivity for $\mathrm{SO}_{2}$. Coordination of the pyridyl $\mathrm{N}$-donor to one axial site of the $\mathrm{Cu}_{2}\left(\mathrm{O}_{2} \mathrm{CR}\right)_{4}$ paddlewheel unit leads to an unusual $(3,36)$-connected $t \boldsymbol{t} \boldsymbol{t}$ framework which, on removal of axial water, affords one open $\mathrm{Cu}$ (II) site per $\mathrm{Cu}_{2}\left(\mathrm{O}_{2} \mathrm{CR}\right)_{4}$ paddlewheel in MFM-170. Significantly, at $298 \mathrm{~K}$ and 1.0 bar, MFM-170 exhibits an unprecedented uptake of $\mathrm{SO}_{2}$ of $17.5 \mathrm{mmol} \mathrm{g}^{-1}$, which can be fully regenerated at ambient temperature. We have unravelled the high selectivity of MFM-170 for $\mathrm{SO}_{2}$ and have probed the nature of host-guest binding using in situ single crystal X-ray diffraction, FTIR micro-spectroscopy and neutron scattering. Importantly, breakthrough experiments of simulated flue gas mixtures demonstrate that MFM-170 has excellent separation properties, even in the presence of water and at elevated temperatures (up to $348 \mathrm{~K}$ ). The stability of MFM-170 to wet $\mathrm{SO}_{2}$ has been confirmed by long duration synchrotron X-ray diffraction experiments. Furthermore, we directly investigate the effect of the open copper sites on $\mathrm{SO}_{2}$ uptake and selectivity by comparing MFM-170 to the coordinatively saturated parent structure MFM-170 $\cdot \mathrm{H}_{2} \mathrm{O}$, in which $\mathrm{H}_{2} \mathrm{O}$ is retained at the axial $\mathrm{Cu}(\mathrm{II})$ site within the $\mathrm{Cu}_{2}\left(\mathrm{O}_{2} \mathrm{CR}\right)_{4}$ paddlewheel.

\section{Results and Discussions}

Synthesis and structural analysis of MFM-170:solv. Solvothermal reaction of a pyridine-containing tetracarboxylate linker 4',4"'-(pyridine-3,5-diyl)bis([1,1'-biphenyl]-3,5-dicarboxylic acid) ( $\mathrm{H}_{4} \mathrm{~L}$, Fig. 1a) and $\mathrm{Cu}\left(\mathrm{NO}_{3}\right)_{2} \cdot 2.5 \mathrm{H}_{2} \mathrm{O}$ in a mixture of DMF and $\mathrm{H}_{2} \mathrm{O}(\mathrm{v} / \mathrm{v}=5: 1)$ under acidic conditions $\left(\mathrm{HNO}_{3}\right)$ yielded blue octahedral crystals of $\left[\mathrm{Cu}_{2}(\mathrm{~L})\left(\mathrm{H}_{2} \mathrm{O}\right)\right] \cdot 6 \mathrm{DMF}$, denoted as MFM-170 $\cdot \mathrm{H}_{2} \mathrm{O} \cdot$ solv. Single crystal X-ray diffraction reveals that MFM-170· $\mathrm{H}_{2} \mathrm{O} \cdot$ solv crystallises in the cubic space group $I m-3 m$ to form a rarely observed (3,36)-connected net with txt topology (Fig. 1b). ${ }^{32-34}$ The metal cluster consists of a $\mathrm{Cu}_{2}\left(\mathrm{O}_{2} \mathrm{CR}\right)_{4}$ paddlewheel with four isophthalate units occupying the equatorial sites and one pyridyl N-donor from the ligand coordinating to the axial site of one $\mathrm{Cu}$ atom. The axial position of the other $\mathrm{Cu}$ atom of the $\mathrm{Cu}_{2}\left(\mathrm{O}_{2} \mathrm{CR}\right)_{4}$ unit is occupied by a water molecule. The framework is constructed from $\mathrm{Cu}_{24}\left(\mathrm{RC}_{6} \mathrm{H}_{3}\left(\mathrm{CO}_{2}\right)_{2}\right)_{24}$ cuboctahedron, which acts as a 36-connected node, joined in a cubic array to six adjacent cuboctahedra by four ligands each (Fig. 1c). The overall framework can be visualised as this smaller cubic net which is connected to a secondary identical net via the 12 corners of the cuboctahedra via $\mathrm{Cu}-\mathrm{N}$ bonds (Fig. 1d). 
Thus, each ligand is a 3-connected node, with two isophthalate moieties that each connect an edge of a cuboctahedron, and one pyridyl $\mathrm{N}$ atom which joins a corner of a cuboctahedron.

The interconnected void spaces in MFM-170 can be considered as three distinct cages, denoted as $\boldsymbol{A}, \boldsymbol{B}$ and $\boldsymbol{C}$ (Fig. 1e). The metal-organic cuboctahedra (denoted as cage $\boldsymbol{A}$ ) have a dimension of $15.9 \AA$, comprised of alternating triangular and square faces. Each square face of cage $\boldsymbol{A}$ joins it to a cage $\boldsymbol{B}$, which is formed by four V-shaped linkers bowing outward to create a prolate pore (width of $16.3 \AA$; length of $22.2 \AA$ ). Cage $\boldsymbol{C}$ is the smallest of the three and connects the triangular faces of cage $\boldsymbol{A}$, measuring $12.8 \AA$ between opposite triangular faces, and $14.2 \AA$ between opposite $\mathrm{C}$ atoms.

Thermal and chemical stability of MFM-170. Thermogravimetric analysis (TGA) of MFM$170 \cdot \mathrm{H}_{2} \mathrm{O} \cdot$ solv shows thermal stability up to $\sim 620 \mathrm{~K}$, confirmed by variable temperature PXRD analysis (Figs. S4, S8). The chemical robustness of MFM-170 $\cdot \mathrm{H}_{2} \mathrm{O} \cdot$ solv was investigated by exposing an assynthesised sample to a range of harsh environmental conditions, including suspending the sample in boiling water and aqueous solutions of $\mathrm{pH}$ between 2-12. No loss in crystallinity was observed by PXRD after exposure to these conditions (Figs. 4b, S2, S3, S6). More importantly, desolvated MFM-170 can be re-hydrated fully and reversibly to give MFM-170. $\mathrm{H} 2 \mathrm{O}$ upon contact with water without loss of crystallinity Reversible water adsorption isotherms at 293 and $303 \mathrm{~K}$ are shown in Fig. S10. To assess the long-term stability of MFM-170 to humid $\mathrm{SO}_{2}$ and water, synchrotron PXRD data were collected for wet $\mathrm{SO}_{2}$-loaded MFM-170 samples every week for 10 weeks (Fig. S7; see SI for further details). No loss of crystallinity or change in the structure of this material was observed (Table S3), confirming the excellent chemical resilience of the framework. The remarkable stability of MFM-170 is attributed to the unusual framework connectivity where the axially-coordinated pyridyl N-donors interlock the two cubic nets and block one of the two axial $\mathrm{Cu}(\mathrm{II})$ sites.

Analysis of gas adsorption isotherms of MFM-170 and MFM-170 $\cdot \mathrm{H}_{2} \mathrm{O}$. Desolvated MFM-170 possesses a BET surface area of $2408 \mathrm{~m}^{2} \mathrm{~g}^{-1}$ (consistent with the calculated surface area of $2456 \mathrm{~m}^{2} \mathrm{~g}^{-1}$ based upon the crystal structure) and a pore volume of $0.88 \mathrm{~cm}^{3} \mathrm{~g}^{-1}$ (calculated from the $\mathrm{N}_{2}$ isotherm at 77 K, Fig. S9), consistent with that $\left(0.87 \mathrm{~cm}^{3} \mathrm{~g}^{-1}\right.$; solvent-accessible void space of $\left.61 \%\right)$ derived from the single crystal structure. Significantly, MFM-170 shows an unprecedented $\mathrm{SO}_{2}$ uptake of $19.4 \mathrm{mmol} \mathrm{g}^{-1}$ (or $1.24 \mathrm{~g} \mathrm{~g}^{-1}$ ) at $273 \mathrm{~K}$ and 1.0 bar (Fig. 3). To the best of our knowledge, this represents the highest known $\mathrm{SO}_{2}$ uptake capacity in porous materials, followed by MFM-601 (16.9 mmol g $\left.{ }^{-1}\right)^{15}$, MFM-202a (13.0 mmol $\left.\mathrm{g}^{-1}\right)^{18}$ and mesoporous silicate MCM-41 (11.6 mmol g-1 $)^{35}$ under the same conditions. The performance of state-of-the-art porous materials under ambient conditions is summarised in Table 1 and Fig. 2, where a general linear relationship between $\mathrm{SO}_{2}$ uptake and BET surface area is observed. MFM-170 exhibits the highest reported $\mathrm{SO}_{2}$ adsorption capacity of $17.5 \mathrm{mmol} \mathrm{g}^{-1}$ at $298 \mathrm{~K}$ and $1.0 \mathrm{bar}$, notably exceeding the current leading MOFs, such as MFM-601 (12.3 mmol g $\left.{ }^{-1}\right)^{15}$, SIFSIX-1-Cu (11.0 mmol g $\left.{ }^{-1}\right)^{16}$, $\left[\mathrm{Zn}_{2}\left(\mathrm{~L}_{1}\right)_{2}\right.$ (bipy)] $\left(10.9 \mathrm{mmol} \mathrm{g}^{-1}\right.$, at $\left.293 \mathrm{~K}\right),{ }^{17}$ and $\mathrm{Ni}(\mathrm{bdc})(\text { ted })_{0.5}\left(10.0 \mathrm{mmol} \mathrm{g}^{-1}\right) .{ }^{19}$ At $298 \mathrm{~K}$ and $1.0 \mathrm{bar}$, the volumetric storage density of $\mathrm{SO}_{2}$ in MFM-170 is 307 times that of gaseous $\mathrm{SO}_{2}$ under the same conditions, or 75 times of that of compressed $\mathrm{SO}_{2}\left(\mathrm{P}_{0}=3.9\right.$ bar) in a pressure vessel (packing efficiency and system volume are not taken into consideration). Furthermore, MFM-170 shows high $\mathrm{SO}_{2}$ adsorption 
at elevated temperatures $\left(11.6 \mathrm{mmol} \mathrm{g}^{-1}\right.$ at $333 \mathrm{~K}$ and 1 bar). Uptake of $\mathrm{SO}_{2}$ in MFM-170 shows a reversible type I isotherm with high uptakes at low pressure (Fig. 3); at $273 \mathrm{~K}$ the uptake at 0.03 bar is $6.5 \mathrm{mmol} \mathrm{g}^{-1}$. Despite the high uptake at low pressure, the excellent reversibility of the $\mathrm{SO}_{2}$ isotherms at 273-333 K indicates that MFM-170 can be fully regenerated under pressure-swing conditions. More significantly, no loss of adsorption capacity of $\mathrm{SO}_{2}$ was detected in MFM-170 after 50 adsorption-desorption cycles at 298 $\mathrm{K}$, and PXRD analysis of MFM-170 after these 50 cycles confirms the full retention of crystal structure, reflecting the exceptional chemical and thermal stability of this material (Fig. 4).

To probe the effect of the open metal sites on $\mathrm{SO}_{2}$ uptake, isotherms were measured for the coordinatively saturated parent material, MFM-170 $\cdot \mathrm{H}_{2} \mathrm{O}$, in which the axial water molecule is retained on the $\mathrm{Cu}(\mathrm{II})$ site. The $\mathrm{SO}_{2}$ isotherm of MFM- $170 \cdot \mathrm{H}_{2} \mathrm{O}$ at $273 \mathrm{~K}$ shows a reduced but still exceptionally high uptake of $\mathrm{SO}_{2}\left(16.2 \mathrm{mmol} \mathrm{g}^{-1}\right)$ (Fig. S15). The difference in adsorption at 1.0 bar between MFM-170 $\mathrm{H}_{2} \mathrm{O}$ and MFM-170 corresponds to approximately twice the density of open $\mathrm{Cu}(\mathrm{II})$ sites $\left(1.46 \mathrm{mmol} \mathrm{\textrm {g } ^ { - 1 }}\right)$, suggesting that the presence of open metal sites has a key role in promoting the $\mathrm{SO}_{2}$ uptake.

In comparison to the high $\mathrm{SO}_{2}$ uptake at $298 \mathrm{~K}$ and 1 bar, MFM-170 uptakes only $3.04 \mathrm{mmol} \mathrm{g}^{-1}$ of $\mathrm{CO}_{2}, 1.33 \mathrm{mmol} \mathrm{g}^{-1}$ of $\mathrm{CH}_{4}, 0.38 \mathrm{mmol} \mathrm{g}^{-1}$ of $\mathrm{CO}$ and $0.28 \mathrm{mmol} \mathrm{g}^{-1}$ of $\mathrm{N}_{2}$ under the same conditions (Figs. 3a, S11-14). The selectivity values of MFM-170 for $\mathrm{SO}_{2} / \mathrm{CO}_{2}, \mathrm{SO}_{2} / \mathrm{N}_{2}, \mathrm{SO}_{2} / \mathrm{CO}$ and $\mathrm{SO}_{2} / \mathrm{CH}_{4}$ were calculated from single component isotherms at $298 \mathrm{~K}$ (Figs. S19, S20). Due to the negligible interaction of $\mathrm{N}_{2}$ with the framework, MFM-170 exhibits a high IAST selectivity of 944 for an equimolar mixture of $\mathrm{SO}_{2} / \mathrm{N}_{2}$ at 1.0 bar. Furthermore, MFM-170 also has high selectivity values of 260, 203 and 35 for $\mathrm{SO}_{2} / \mathrm{CH}_{4}$, $\mathrm{SO}_{2} / \mathrm{CO}$ and $\mathrm{SO}_{2} / \mathrm{CO}_{2}$, respectively. More importantly and considering the relatively low concentrations of $\mathrm{SO}_{2}$ present in flue gas, decreasing the $\mathrm{SO}_{2}: \mathrm{X}$ ratio from 50:50 to 1:99 still affords high selectivity values for $\mathrm{SO}_{2} / \mathrm{N}_{2}$ (260) and $\mathrm{SO}_{2} / \mathrm{CO}_{2}(28)$. These values are lower than those reported for SIFSIX-2-Cu-i, ${ }^{16}$ which possesses much narrower pores than MFM-170.

\section{Determination of the binding domains for adsorbed $\mathrm{SO}_{2}$ molecules in MFM-170 and MFM-}

170 $\cdot \mathrm{H}_{2} \mathrm{O}$. The binding domains of $\mathrm{SO}_{2}$ were studied using in situ synchrotron X-ray single crystal diffraction. Structural analysis of desolvated MFM-170 confirms the complete removal of free solvents in the pore and bound water molecules on the $\mathrm{Cu}$ (II) sites, generating twelve open $\mathrm{Cu}$ (II) sites on the internal surface of cage $\boldsymbol{A}$ in desolvated MFM-170. Refinement of the diffraction data for the $\mathrm{SO}_{2}$-loaded sample at $298 \mathrm{~K}$ revealed significant residual electron densities which were sequentially assigned as six distinct binding sites (1-6) in order of decreasing occupancy, giving a formula of $\left[\mathrm{Cu}_{2}(\mathrm{~L})\left(\mathrm{SO}_{2}\right)_{0.67}\right]\left(\mathrm{SO}_{2}\right)_{4.79}$ (denoted as MFM-170·5.46SO $\mathrm{SO}_{2}$ (Fig. 5). Interestingly, the smallest cage $\boldsymbol{C}$ accounts for $\sim 45 \%$ of all located $\mathrm{SO}_{2}$ molecules, whilst $\sim 25 \%$ is found in the cuboctahedral cage $\boldsymbol{A}$. No ordered $\mathrm{SO}_{2}$ molecules were located in the largest cage $\boldsymbol{B}$ reflecting the large void space and lack of functional groups lining the pore.

The primary binding site, $\mathbf{1}$, is situated on a three-fold rotational axis in the triangular window of cage $\boldsymbol{A}$ and has full occupancy. The $\mathrm{S}_{\mathrm{SO}_{2}}$ atom points towards the $\mathrm{Cu}_{2}\left(\mathrm{O}_{2} \mathrm{CR}\right)_{4}$ paddlewheel, forming close contacts with two carboxylate $\mathrm{O}$ centers $\left[\mathrm{S}_{\mathrm{SO}_{2}}\left(\delta^{+}\right) \cdots\left(\delta^{-}\right) \mathrm{O}=3.16(3) \AA\right]$. Simultaneously, the $\mathrm{O}_{\mathrm{SO}_{2}}$ atom located in the centre of the window forms a three-fold supplementary interaction to the isophthalate $\mathrm{C}-\mathrm{H}$ 
groups lining the window $\left[\mathrm{O}_{\mathrm{SO}_{2}} \cdots \mathrm{C}=4.18(3) \AA,<\mathrm{O} \cdots \mathrm{H}-\mathrm{C}=140.5(6)^{\circ}\right] . \mathrm{SO}_{2}(2)$ is coordinated to the open $\mathrm{Cu}$ (II) site in an end-on manner $\left[\mathrm{O}_{\mathrm{SO}_{2}}-\mathrm{Cu}=2.28(10) \AA\right]$ with an occupancy of 0.67. The $\mathrm{O}_{\mathrm{SO}_{2}}-\mathrm{Cu}$ bond distance is shorter than the sum of van der Waals radius of $\mathrm{Cu}$ and $\mathrm{O}(2.92 \AA)$, confirming the formation of a covalent bond. The two $\mathrm{O}_{\mathrm{SO}_{2}}$ atoms are parallel to the $\mathrm{Cu} \cdots \mathrm{Cu}$ axis, whilst the $\mathrm{S}_{\mathrm{SO}_{2}}$ is disordered about a $\mathrm{C}_{2}$ axis. Significantly, this is the first crystallographic example of $\mathrm{SO}_{2}$ coordination at open metal sites within a MOF structure. Remarkably, the $\mathrm{Cu}$ (II) center is not the most occupied site, which is at least in part due to steric hindrance created by site $\mathbf{1}$; the twelve $\mathrm{Cu}$ (II) sites line the internal surface of cage $\boldsymbol{A}$ and are therefore accessed through the square faces as the triangular windows are fully occupied by $\mathrm{SO}_{2}$ molecules.

$\mathrm{SO}_{2}(3)$ (occupancy $=0.47$ ) is located in a crevice between cage $\boldsymbol{B}$ of one net and a perpendicular cage $\boldsymbol{B}$ of the second net. This small pocket accommodates interactions with the face of the pyridine ring $\left[\mathrm{S}_{\mathrm{SO}_{2}} \cdots \mathrm{N}=3.48(18) \AA\right]$ and phenyl $\mathrm{H}$ atoms $\left[\mathrm{O}_{\mathrm{SO}_{2}} \cdots \mathrm{C}^{4}=3.20(4) \AA, \mathrm{O}_{\mathrm{SO}_{2}} \cdots \mathrm{C}^{11}=4.80(4) \AA\right]$, accounting for $\sim 30 \%$ of all located $\mathrm{SO}_{2}$ molecules. $\mathrm{SO}_{2}(4)$ (occupancy $=0.32$ ), is found in cage $\boldsymbol{C}$ and situated with the $\mathrm{S}$ atom facing the carboxylate oxygens of the paddlewheel $\left[\mathrm{S}_{\mathrm{SO}_{2}}\left(\delta^{+}\right) \cdots\left(\delta^{-}\right) \mathrm{O}^{1}=3.67(3) \AA\right]$ and interacts with neighbouring phenyl rings $\left[\mathrm{O}_{\mathrm{SO}_{2}} \cdots \mathrm{C}^{7}=3.70(5) \AA, \mathrm{O}_{\mathrm{sO}_{2}} \cdots\right.$ ring centroid $\left.=3.26(5) \AA\right] . \mathrm{SO}_{2}(5)$ is found in the square face between cages $\boldsymbol{A}$ and $\boldsymbol{B}$ with an occupancy of 0.26 . Whilst no significant interaction with the framework was identified, dipole interactions between the adsorbed $\mathrm{SO}_{2}$ molecules were observed $\left[\mathrm{S}_{\mathrm{SO}_{2(2)}} \cdots \mathrm{O}_{\mathrm{SO}_{2(5)}}=2.54(6) \AA, \mathrm{O}_{\mathrm{SO}_{2(5)}} \cdots \mathrm{S}_{\mathrm{SO}_{2(6)}}=2.88(5) \AA\right]$. The least populated site (6) (occupancy $\left.=0.23\right)$ is sandwiched between two phenyl rings in cage $C$ and forms interactions between the $\mathrm{S}\left(\delta^{+}\right)$and the phenyl $\pi$-electrons at distances of 3.28(15) and 3.30(15) $\AA$, measured between the ring centroids and $\mathrm{S}_{\mathrm{SO}_{2}}$.

We sought to examine the most thermodynamically favoured site via controlled desorption of MFM-170·5.46 $\mathrm{SO}_{2}$. Crucially, diffraction data collected for the sample under dynamic vacuum at $298 \mathrm{~K}$ showed that almost all adsorbed $\mathrm{SO}_{2}$ molecules were removed from the structure of MFM-170, leaving just the $\mathrm{Cu}$ (II)-bound $\mathrm{SO}_{2}$ (2) with an occupancy of 0.09 . This confirms that the $\mathrm{Cu}(\mathrm{II})$ site is indeed the thermodynamically strongest binding site but is sufficiently weak to be almost entirely desorbed on reduction of pressure. Interestingly, DFT calculations indicated that for MOF-74(M) (M = Mg, Ni, Co, Zn), the sites with highest binding energies for $\mathrm{SO}_{2}$ were located at the open metal sites. ${ }^{37}$ For MFM-170 the multi-site cooperative binding between $\mathrm{SO}_{2}$ molecules results in an optimal balance of high selectivity and excellent reversibility of the $\mathrm{SO}_{2}$ adsorption that is observed. Subsequent brief heating to $400 \mathrm{~K}$ fully regenerated MFM-170 without any loss of crystallinity.

To investigate the nature of $\mathrm{SO}_{2}$ binding in the absence of open metal sites, a single crystal of MFM-170 $\cdot \mathrm{H}_{2} \mathrm{O} \cdot$ solv was activated under mild conditions to remove free solvent molecules whilst leaving the axial water molecule bound to the $\mathrm{Cu}$ centre. The resultant MFM-170 $\cdot \mathrm{H}_{2} \mathrm{O}$ was loaded with 1 bar $\mathrm{SO}_{2}$ and subsequent refinement of the diffraction data gave a structure with formula of $\left[\mathrm{Cu}_{2}(\mathrm{~L})\left(\mathrm{H}_{2} \mathrm{O}\right)_{0.79}\right]\left(\mathrm{SO}_{2}\right)_{3.27}$ (denoted MFM-170· $\mathrm{H}_{2} \mathrm{O} \cdot 3.27 \mathrm{SO}_{2}$ ). Significantly, of the six $\mathrm{SO}_{2}$ molecules previously located in MFM-170.5.46 $\mathrm{SO}_{2}$, four are also present in MFM-170 $\cdot \mathrm{H}_{2} \mathrm{O} \cdot 3.27 \mathrm{SO}_{2}$ (Fig. S26). Clearly, the site $\mathrm{Cu}(\mathrm{II})$-bound $\mathrm{SO}_{2}(2)$ was absent in MFM-170 $\cdot \mathrm{H}_{2} \mathrm{O} \cdot 3.27 \mathrm{SO}_{2}$, and as $\mathrm{SO}_{2}(2)$ is a primary 
site of interaction for $\mathrm{SO}_{2}(\mathbf{5})$, the latter was not located either. However, overall the structural analysis shows that saturation of the copper sites in MFM-170 with $\mathrm{H}_{2} \mathrm{O}$ does not greatly reduce the $\mathrm{SO}_{2}$ binding capacity, consistent with the retention of high uptake capacity in MFM-170 $\cdot \mathrm{H}_{2} \mathrm{O}$.

In situ spectroscopic analysis of host-guest binding dynamics. In situ FTIR spectroscopic studies were conducted for MFM-170 as a function of $\mathrm{SO}_{2}$ loading (Fig. 6). The growth of a new peak at $1143 \mathrm{~cm}^{-}$

${ }^{1}$ was assigned to the $v_{1}$ symmetric stretch of adsorbed $\mathrm{SO}_{2}$, which increases as a function of $\mathrm{SO}_{2}$ partial pressure (pp). This symmetric band is red-shifted from $1152 \mathrm{~cm}^{-1}\left(\Delta=-9 \mathrm{~cm}^{-1}\right)$ for free $\mathrm{SO}_{2}$, confirming its interaction with the framework. A second new band, assigned to the $v_{3}$ asymmetric stretch of adsorbed $\mathrm{SO}_{2}$, grows and red-shifts from $1340 \mathrm{~cm}^{-1}$ at $0.01 \mathrm{ppSO}_{2}$ to $1320 \mathrm{~cm}^{-1}$ at $0.10 \mathrm{ppSO}_{2}$. These bands show larger shifts compared to gas phase $\mathrm{SO}_{2}\left(\Delta=-41 \mathrm{~cm}^{-1}\right.$ at $\left.0.10 \mathrm{ppSO}_{2}\right)$, but are consistent with physisorption of $\mathrm{SO}_{2} \cdot 37,38$

Significant vibrational changes of the framework were also observed on $\mathrm{SO}_{2}$ adsorption. The carboxylate $v_{\text {as }}(\mathrm{COO})$ mode at $1658 \mathrm{~cm}^{-1}$ and $v_{\mathrm{s}}(\mathrm{COO})$ mode at $1470 \mathrm{~cm}^{-1}$ of MFM-170 decrease in intensity and are red-shifted to $1648 \mathrm{~cm}^{-1}\left(\Delta=-10 \mathrm{~cm}^{-1}\right)$ and $1462 \mathrm{~cm}^{-1}\left(\Delta=-8 \mathrm{~cm}^{-1}\right)$ at $0.50 \mathrm{ppSO}_{2}$, respectively. Interestingly, this is distinct from the blue-shifts of these bands observed in previously reported MOFs on $\mathrm{SO}_{2}$ loading. ${ }^{19}$ This is likely due to the lack of open metal sites in those reported structures, and therefore is consistent with interactions of $\mathrm{SO}_{2}$ with the $\mathrm{Cu}$ site in MFM-170. Furthermore, a red-shift $\left(\triangle=-16 \mathrm{~cm}^{-}\right.$ ${ }^{1}$ ) of the band at $1595 \mathrm{~cm}^{-1}$ on $\mathrm{SO}_{2}$ binding, assigned to the pyridine ring vibrational band $v(\mathrm{CC} / \mathrm{CN})$, suggests a weakening of the pyridine $\mathrm{N}-\mathrm{Cu}$ coordination on $\mathrm{SO}_{2}$ adsorption. ${ }^{39}$

In situ INS experiments were conducted for dry and wet MFM-170 to gain further insight into the dynamics of $\mathrm{SO}_{2}$ binding (Figs. 6, S24). Comparison of the spectra of bare MFM-170 and MFM-170 $\cdot \mathrm{H}_{2} \mathrm{O}$ allows clear assignment of peaks assigned to water with a translational mode at $30 \mathrm{meV}$, rocking mode at $48 \mathrm{meV}$ and wagging and twisting modes at 61 and $66 \mathrm{meV}$. The peak observed at $8.3 \mathrm{meV}$ in the bare $\mathrm{MOF}$ can be attributed to a lattice mode which, on $\mathrm{SO}_{2}$ loading, increases in intensity and shifts to $9.2 \mathrm{meV}$, suggesting a stiffening effect in MFM-170 on $\mathrm{SO}_{2}$ binding. Overall, there is lack of change to the INS features upon $\mathrm{SO}_{2}$ adsorption in MFM-170, indicating a moderate-to-weak host-guest interaction, fully consistent with the reversibility of $\mathrm{SO}_{2}$ adsorption and full retention of the crystal structure of MFM-170 on regeneration. Upon $\mathrm{SO}_{2}$ loading of MFM-170 $\cdot \mathrm{H}_{2} \mathrm{O}$, notable spectral changes are observed, attributed to interactions between bound water and $\mathrm{SO}_{2}$ molecules. The broad translational band increases in intensity, whilst the water rocking mode increases in intensity with a blue-shift from 48 to $49 \mathrm{meV}$. The librational mode at $66 \mathrm{meV}$ also blue-shifts to $67 \mathrm{meV}$ with a decrease in intensity. Importantly, subsequent activation of the $\mathrm{SO}_{2}$-adsorbed MFM-170 $\cdot \mathrm{H}_{2} \mathrm{O}$ at $373 \mathrm{~K}$ under vacuum removed all peaks assigned to water, and led to a spectrum consistent with the dry bare MOF, further evidencing the stability of the MOF to humid $\mathrm{SO}_{2}$.

Dynamic breakthrough separation of $\mathrm{SO}_{2}$ in MFM-170. To test the effect of humidity on $\mathrm{SO}_{2}$ adsorption in MFM-170, dynamic breakthrough experiments were conducted using gas mixtures of either 99.75\% He and $2500 \mathrm{ppm} \mathrm{SO}_{2}$ or $98.25 \% \mathrm{He}, 1.5 \% \mathrm{H}_{2} \mathrm{O}, 2500 \mathrm{ppm} \mathrm{SO}_{2}$ (Fig. 3c). Due to the experimental set-up, He was used instead of $\mathrm{N}_{2}$ as a non-interacting component (see SI for details). Under dry conditions, $\mathrm{SO}_{2}$ begins to breakthrough at dimensionless time $\tau=420$ and reaches a maximum by $\tau=1400$. With the 
addition of $1.5 \%$ water, MFM-170 exhibits a slightly reduced SO2 retention time at $\tau=370$. Importantly, three cycles of SO2 breakthrough and desorption (1 x dry cycle and $2 \mathrm{x}$ wet cycles; Fig 3c) confirmed no significant deterioration in performance. To investigate further the separation ability for $\mathrm{SO}_{2} / \mathrm{CO}_{2}$, breakthrough experiments were also carried out using simulated flue gas mixtures for a fully-activated sample and a water-saturated sample of MFM-170 (81.6-84.8\% He, 15-18\% $\mathrm{CO}_{2}$ and 2500-4050 ppm SO Fig. 3d). For the dry sample, the breakthrough curve at $298 \mathrm{~K}$ shows that $\mathrm{CO}_{2}$ is the first component eluted through the fixed-bed packed of MFM-170 and breaks through at dimensionless time $\tau=14$. In comparison, $\mathrm{SO}_{2}$ was selectively retained by MFM-170 and breaks through much later $(\tau=\sim 350)$ with maximum output observed by $\tau=1450$. After the breakthrough of $\mathrm{SO}_{2}$, the packed bed was regenerated at $298 \mathrm{~K}$ by flowing pure helium through it, and this results in rapid desorption of both $\mathrm{CO}_{2}$ and $\mathrm{SO}_{2}$. No more $\mathrm{SO}_{2}$ was detected in the effluent stream when the temperature was subsequently increased to $423 \mathrm{~K}$, indicating the complete desorption of $\mathrm{SO}_{2}$ and regeneration of MFM-170 at $298 \mathrm{~K}$. Crucially, the ability of MFM-170 to separate $\mathrm{SO}_{2}$ from $\mathrm{CO}_{2}$ in the presence of a large quantity of water was confirmed by repeating the breakthrough experiments with a water-saturated fixed-bed. The column was exposed to a stream of $3 \% \mathrm{H}_{2} \mathrm{O}$ in $\mathrm{He}$ until breakthrough and saturation of water was observed. The subsequent breakthrough experiment demonstrated excellent $\mathrm{SO}_{2} / \mathrm{CO}_{2}$ separation under these conditions (Fig. 3d). Interestingly, whilst the breakthrough times were slightly decreased for both components than in the above experiments, $\mathrm{CO}_{2}$ is affected more severely with a much steeper breakthrough. Unlike the dry sample, a significant roll-up effect is observed for $\mathrm{CO}_{2}$ under humid conditions, indicating a large displacement of weakly bound $\mathrm{CO}_{2}$ by $\mathrm{SO}_{2}$, likely due to the formation of $\mathrm{H}_{2} \mathrm{SO}_{3}$ complexes in the pore. This suggests that the $\mathrm{SO}_{2} / \mathrm{CO}_{2}$ separation in MFM-170 could be enhanced under humid conditions. It has been suggested that 313-333 K represents a temperature range that is suitable for purifying flue gas streams from coal-fired powerplants. ${ }^{2,3}$ Therefore, breakthrough experiments were also attempted for an activated packed bed of MFM-170 at elevated temperatures of 323 and $348 \mathrm{~K}$ (Fig. S25). Importantly, a very clear separation between $\mathrm{CO}_{2}$ and $\mathrm{SO}_{2}$ is evident at both temperatures, though, as expected, with reduced retention time.

\section{Conclusions}

The development of efficient strategies to fully mitigate emissions of $\mathrm{SO}_{2}$ from combustion and to achieve efficient $\mathrm{SO}_{2}$ storage and safe transport remains a fundamental challenge for many industries, power-plants and marine transport sectors. Although emerging MOF materials show great promise as sorbents for a wide range of inert gases, relatively little success has been achieved on the adsorptive removal of $\mathrm{SO}_{2}$, primarily due to the generally limited reversibility and/or stability of MOFs upon contact with highly corrosive $\mathrm{SO}_{2}$. The present work describes a high $\mathrm{SO}_{2}$ uptake of $17.5 \mathrm{mmol} \mathrm{g}^{-1}$ at ambient conditions in a remarkably stable MOF with open $\mathrm{Cu}(\mathrm{II})$ sites with high selectivity for $\mathrm{SO}_{2}$ over $\mathrm{CO}_{2}$ and $\mathrm{N}_{2}$. The binding sites of $\mathrm{SO}_{2}$ in MFM-170 have been elucidated using in situ single crystal diffraction which revealed the reversible coordination of $\mathrm{SO}_{2}$ at open $\mathrm{Cu}$ (II) sites and five other binding sites at crystallographic resolution. Crucially, the open $\mathrm{Cu}(\mathrm{II})$ site has been identified as the most thermodynamically favoured binding site for $\mathrm{SO}_{2}$. In addition to static crystallography studies, dynamic 
vibrational modes were investigated using INS and FT-IR microscopy as a function of $\mathrm{SO}_{2}$ loading. The industrial promise of MFM-170 has been demonstrated through dynamic breakthrough experiments which showed efficient separation of $\mathrm{SO}_{2}$ from simulated flue gas mixtures, even in the presence of water and at elevated temperatures.

\section{References.}

1. Rezaei, F. et al. $\mathrm{SO}_{\mathrm{x}} / \mathrm{NO}_{\mathrm{x}}$ Removal from flue gas streams by solid adsorbents: a review of current challenges and future directions. Energy \& Fuels 29, 5467-5486 (2015).

2. Gao, J. et al Pilot-scale experimental study on the $\mathrm{CO}_{2}$ capture process with existing of $\mathrm{SO}_{2}$ : degradation, reaction rate, and mass transfer. Energy \& Fuels 25, 5802-5809 (2011).

3. Ding, S. et al. Significant promotion effect of Mo additive on a novel $\mathrm{Ce}-\mathrm{Zr}$ mixed oxide catalyst for the selective catalytic reduction of $\mathrm{NO}_{x}$ with $\mathrm{NH}_{3}$. ACS Appl. Mater. Interfaces 7, 9497-9506 (2015).

4. Kinnunen, N. M. et al. Case study of a modern lean-burn methane combustion catalyst for automotive applications: What are the deactivation and regeneration mechanisms? Appl. Catal. B Environ. 207, 114-119 (2017).

5. Han, X., Yang, S., Schröder, M. Porous metal-organic frameworks as emerging sorbents for clean air. Nat. Rev. Chem., 3, 108-118 (2019).

6. Raymundo-Piñero, E. et al. Factors controling the $\mathrm{SO}_{2}$ removal by porous carbons: relevance of the $\mathrm{SO}_{2}$ oxidation step. Carbon, 38, 335-344 (2000).

7. Mathieu, Y. et al. Adsorption of $\mathrm{SO}_{\mathrm{x}}$ by oxide materials: A review. Fuel Process. Technol. 114, 81-100 (2013).

8. Kohl, A. L. \& Nielsen, R. Gas Purification. (Gulf Professional Publishing, 1997).

9. Nabais, A. R. et al. $\mathrm{CO}_{2} / \mathrm{N}_{2}$ gas separation using $\mathrm{Fe}(\mathrm{BTC})$-based mixed matrix membranes: a view on the adsorptive and filler properties of metal-organic frameworks. Sep. Purif. Technol. 202, 174-184 (2018).

10. Peng, J. et al. Efficient kinetic separation of propene and propane using two microporous metal organic frameworks. Chem. Commun. 53, 9332-9335 (2017).

11. Chen, D.-M. et al. Tunable robust pacs-MOFs: a platform for systematic enhancement of the $\mathrm{C}_{2} \mathrm{H}_{2}$ uptake and $\mathrm{C}_{2} \mathrm{H}_{2} / \mathrm{C}_{2} \mathrm{H}_{4}$ separation performance. Inorg. Chem. 57, 2883-2889 (2018).

12. Zhong, R. et al. A solvent 'squeezing' strategy to graft ethylenediamine on $\mathrm{Cu}_{3}(\mathrm{BTC})_{2}$ for highly efficient $\mathrm{CO}_{2} / \mathrm{CO}$ separation. Chem. Eng. Sci. 184, 85-92 (2018).

13. Zhang, Z. et al. MOFs for $\mathrm{CO}_{2}$ capture and separation from flue gas mixtures: the effect of multifunctional sites on their adsorption capacity and selectivity. Chem. Commun. 49, 653-661 (2013).

14. Peralta, D. et al. Comparison of the behavior of metal-organic frameworks and zeolites for hydrocarbon separations. J. Am. Chem. Soc. 134, 8115-8126 (2012).

15. Carter, J. H. et al. Exceptional adsorption and binding of sulfur dioxide in a robust zirconium-based metalorganic framework. J. Am. Chem. Soc. 140, 15564-15567 (2018).

16. Cui, X. et al. Ultrahigh and selective $\mathrm{SO}_{2}$ uptake in inorganic anion-pillared hybrid porous materials. Adv. Mater. 29, 1606929 (2017).

17. Glomb, S. et al. Metal-organic frameworks with internal urea-functionalized dicarboxylate linkers for $\mathrm{SO}_{2}$ and $\mathrm{NH}_{3}$ adsorption. ACS Appl. Mater. Interfaces 9, 37419-37434 (2017). 
18. Yang, S. et al. Irreversible network transformation in a dynamic porous host catalyzed by sulfur dioxide. J. Am. Chem. Soc. 135, 4954-4957 (2013).

19. Tan, K. et al. Mechanism of preferential adsorption of $\mathrm{SO}_{2}$ into two microporous paddle wheel frameworks $\mathrm{M}(\mathrm{bdc})(\mathrm{ted})_{0.5}$. Chem. Mater. 25, 4653-4662 (2013).

20. Savage, M. et al. Selective adsorption of sulfur dioxide in a robust metal-organic framework material. Adv. Mater. 28, 8705-8711 (2016).

21. Li, L. et al. Post-synthetic modulation of the charge distribution in a metal-organic framework for optimal binding of carbon dioxide and sulfur dioxide. Chem. Sci. 10, 1472-1482 (2019).

22. Lee, G.-Y. et al. Amine-functionalized covalent organic framework for efficient $\mathrm{SO}_{2}$ capture with high reversibility. Sci. Rep. 7, 557 (2017).

23. Thallapally, P. K. et al. Prussian blue analogues for $\mathrm{CO}_{2}$ and $\mathrm{SO}_{2}$ capture and separation applications. Inorg. Chem. 49, 4909-4915 (2010).

24. Fernandez, C. et al. Gas-induced expansion and contraction of a fluorinated metal-organic framework. Cryst. Growth Des. 10, 1037-1039 (2010).

25. Tchalala, M. R. et al. Fluorinated MOF platform for selective removal and sensing of $\mathrm{SO}_{2}$ from flue gas and air. Nat. Commun. 10, 1328 (2019).

26. Riboldi, L. \& Bolland, O. Overview on pressure swing adsorption (PSA) as $\mathrm{CO}_{2}$ capture technology: state-ofthe-art, limits and potentials. Energy Procedia 114, 2390-2400 (2017).

27. Riboldi, L. \& Bolland, O. Evaluating pressure swing adsorption as a $\mathrm{CO}_{2}$ separation technique in coal-fired power plants. Int. J. Greenh. Gas Control 39, 1-16 (2015).

28. Britt, D. et al. Highly efficient separation of carbon dioxide by a metal-organic framework replete with open metal sites. Proc. Natl. Acad. Sci. 106, 20637-20640 (2009).

29. Wong-Foy, A. G., Matzger, A. J. \& Yaghi, O. M. Exceptional $\mathrm{H}_{2}$ saturation uptake in microporous metal-organic frameworks. J. Am. Chem. Soc. 128, 3494-3495 (2006).

30. Caskey, S. R., Wong-Foy, A. G. \& Matzger, A. J. Dramatic tuning of carbon dioxide uptake via metal substitution in a coordination polymer with cylindrical pores. J. Am. Chem. Soc. 130, 10870-10871 (2008).

31. Britt, D., Tranchemontagne, D. \& Yaghi, O. M. Metal-organic frameworks with high capacity and selectivity for harmful gases. Proc. Natl. Acad. Sci. 105, 11623-11627 (2008).

32. Guillerm, V. et al. A supermolecular building approach for the design and construction of metal-organic frameworks. Chem. Soc. Rev. 43, 6141-6172 (2014).

33. Park, J. et al. A versatile metal-organic framework for carbon dioxide capture and cooperative catalysis. Chem. Commun. 48, 9995 (2012).

34. Lu, Z. et al. The utilization of amide groups to expand and functionalize metal-organic frameworks simultaneously. Chem. - A Eur. J. 22, 6277-6285 (2016).

35. Branton, P. J., Hall, P. G., Treguer, M. \& Sing, K. S. W. Adsorption of carbon dioxide, sulfur dioxide and water vapour by MCM-41, a model mesoporous adsorbent. J. Chem. Soc., Faraday Trans. 91, 2041-2043 (1995).

36. Goodman, A. L., Li, P., Usher, C. R. \& Grassian, V. H. Heterogeneous uptake of sulfur dioxide on aluminum and magnesium oxide particles. J. Phys. Chem. A 105, 6109-6120 (2001).

37. Tan, K. et al. Interaction of acid gases $\mathrm{SO}_{2}$ and $\mathrm{NO}_{2}$ with coordinatively unsaturated metal organic frameworks: MOF-74 (M = Zn, Mg, Ni, Co). Chem. Mater. 29, 4227-4235 (2017).

38. Schneider, W. F., Li, J. \& Hass, K. C. Combined computational and experimental investigation of $\mathrm{SO}_{\mathrm{x}}$ adsorption on MgO. J. Phys. Chem. B 105, 6972-6979 (2001). 
39. Marinho, M. V. et al. Synthesis, crystal structure, and spectroscopic characterization of trans-bis $[(\mu-1,3-b i s(4-$ pyridyl)propane)( $\mu$-(3-thiopheneacetate- $O))(3$-thiopheneacetate- $O)] \operatorname{dicopper}(\mathrm{II}), \quad\left\{\left[\mathrm{Cu}_{2}\left(\mathrm{O}_{2} \mathrm{CCH}_{2} \mathrm{C}_{4} \mathrm{H}_{3} \mathrm{~S}\right)_{4} \quad \mu\right.\right.$ $\left.\left.(\mathrm{BPP})_{2}\right]\right\}_{n}$ : from a dinuclear paddle-wheel copper(II) unit to a 2-D coordination polymer involving monatomic carboxylate bridges. Inorg. Chem. 43, 1539-1544 (2004).

\section{Methods}

SO2 safety: All systems involved in the supply, delivery and measurement of $\mathrm{SO}_{2}$ were rigorously leak tested and used only within range of a $\mathrm{SO}_{2}$ detection system with a sensitivity of $0.1 \mathrm{ppm}$. All gases exhausted from experimental apparatus were diluted with a flow of $\mathrm{N}_{2}$ and fed into fume hood extracts.

Synthesis of MFM-170·solv: $\left[\mathrm{Cu}_{2}\left(\mathrm{C}_{33} \mathrm{H}_{17} \mathrm{NO}_{8}\right)\left(\mathrm{H}_{2} \mathrm{O}\right)\right] \cdot 6\left(\mathrm{C}_{3} \mathrm{H}_{7} \mathrm{NO}\right): \mathrm{H}_{4} \mathrm{~L}(192 \mathrm{mg}, 0.36 \mathrm{mmol})$ and $\mathrm{Cu}\left(\mathrm{NO}_{3}\right)_{2} \cdot 2.5 \mathrm{H}_{2} \mathrm{O}$ (298 mg, $1.28 \mathrm{mmol})$ were dissolved in a solution of DMF: $\mathrm{H}_{2} \mathrm{O}(48 \mathrm{~mL}, 5: 1)$ and acidified with conc. $\mathrm{HNO}_{3}(0.3$ $\mathrm{mL}$ ). The solution was heated in a Schott bottle at $80^{\circ} \mathrm{C}$ for $18 \mathrm{~h}$ until blue octahedral crystals precipitated. The product was filtered, washed with hot DMF and dried in air (320 mg, 86\%). IR (ATR) cm ${ }^{-1}: 3382$ (b), 1698 (w), 1645 (s), 1598 (s), 1557 (s), 1428 (s), 1378 (vs), 1298 (s), 1244 (w), 1170 (w), 1116 (m). Elemental analysis (\% calculated/found): C 53.46/52.93; $\mathrm{H} 4.89 / 4.61 ; \mathrm{N}$ 6.93/7.18. Powder samples of MFM-170· $\mathrm{H}_{2} \mathrm{O} \cdot$ solv in this work were obtained by stirring identical reaction mixtures in an open round bottom flask. Whilst the sum formula from single crystal $X$-ray diffraction included in the refinement model is $\mathrm{Cu}_{2}\left(\mathrm{C}_{33} \mathrm{H}_{17} \mathrm{NO}_{8}\right)\left(\mathrm{H}_{2} \mathrm{O}\right)_{0.65}$, the final formula of $\left[\mathrm{Cu}_{2}\left(\mathrm{C}_{33} \mathrm{H}_{17} \mathrm{NO}_{8}\right)\left(\mathrm{H}_{2} \mathrm{O}\right)\right] \cdot 6\left(\mathrm{C}_{3} \mathrm{H}_{7} \mathrm{NO}\right)$ was calculated from a combination of TGA and elemental analysis, accounting for disordered solvent molecules.

Gas Cell Details and Structure Determination and Refinement of MFM-170 $\cdot \mathrm{H}_{2} \mathrm{O} \cdot \operatorname{solv}$, MFM-170, MFM-

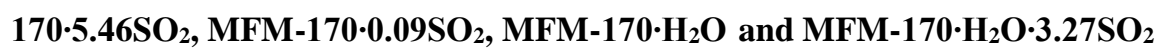

Gas-loaded single crystal X-ray diffraction experiments of MFM-170 were carried out at beamline 11.3.1 of the Advanced Light Source, Berkeley. Single crystals of MFM-170 were placed in a capillary gas handling cell and were evacuated in situ under a hot stream of $\mathrm{N}_{2}$ centred on the capillary. The activated crystals were then cooled to $c a .300$ $\mathrm{K}$ before being dosed with 1 bar of $\mathrm{SO}_{2}$. The locations of the $\mathrm{SO}_{2}$ molecules could be discerned from the Fourier difference maps at $300 \mathrm{~K}\left(\mathrm{MFM}-170 \cdot 5.46 \mathrm{SO}_{2}, \mathrm{MFM}-170 \cdot 0.09 \mathrm{SO}_{2}\right)$ and $260 \mathrm{~K}\left(\mathrm{MFM}-170 \cdot \mathrm{H}_{2} \mathrm{O} \cdot 3.27 \mathrm{SO}_{2}\right)$ and were included in the refinement model with bond distances and angles constrained to ideal values. See Supplementary Information for details of structure determination and refinement.

Crystal Data for MFM-170· $\mathrm{H}_{2} \mathrm{O} \cdot \mathbf{s o l v}\left[\mathrm{Cu}_{2}\left(\mathrm{C}_{33} \mathrm{H}_{17} \mathrm{NO}_{8}\right)\left(\mathrm{H}_{2} \mathrm{O}\right)_{0.65}\right]$; blue octahedron $(0.1 \times 0.1 \times 0.1 \mathrm{~mm})$. Cubic, Im$3 m, \mathrm{a}=33.5294(17) \AA, \mathrm{V}=37963(7) \AA, \mathrm{Z}=24, \rho_{\text {calcd }}=0.729 \mathrm{~g} \mathrm{~cm}^{-1} \cdot \mu_{\text {calcd }}=0.883 \mathrm{~mm}^{-1}, \mathrm{~F}(000)=8413$. A total of 45304 reflections were collected, of which 1475 were unique giving $\mathrm{R}$ int $=0.153$. Final $\mathrm{R}_{1}\left(w \mathrm{R}_{2}\right)=0.0465(0.1226)$ with $\mathrm{GoF}=1.130$. The final difference Fourier extreme were 0.427 and $-0.568 \mathrm{e}^{-3}$.

Crystal Data for desolvated MFM-170 $\left[\mathrm{Cu}_{2}\left(\mathrm{C}_{33} \mathrm{H}_{17} \mathrm{NO}_{8}\right)\right]$; purple octahedron $(0.1 \times 0.1 \times 0.1 \mathrm{~mm})$. Cubic, Im-3m, $\mathrm{a}=33.609(2) \AA, \mathrm{V}=37694(6) \AA, \mathrm{Z}=24, \rho_{\text {calcd }}=0.722 \mathrm{~g} \mathrm{~cm}^{-1} \cdot \mu_{\text {calcd }}=0.883 \mathrm{~mm}^{-1}, \mathrm{~F}(000)=8256$. A total of 42452 reflections were collected, of which 1043 were unique giving $\mathrm{R}$ int $=0.197$. Final $\mathrm{R}_{1}\left(w \mathrm{R}_{2}\right)=0.039(0.097)$ with GoF $=1.045$. The final difference Fourier extreme were 0.320 and $-0.381 \mathrm{e}^{-3}$.

Crystal Data for MFM-170.5.46SO $2 ~\left[\mathrm{Cu}_{2}\left(\mathrm{C}_{33} \mathrm{H}_{17} \mathrm{NO}_{8}\right)\left(\mathrm{SO}_{2}\right)_{0.67}\right]\left(\mathrm{SO}_{2}\right)_{4.79}$; blue octahedron $(0.1 \times 0.1 \times 0.1 \mathrm{~mm})$. Cubic, Im-3m, a =33.5808(17) $\AA, \mathrm{V}=37868(6) \AA, \mathrm{Z}=24, \rho_{\text {calcd }}=1.086 \mathrm{~g} \mathrm{~cm}^{-1} . \mu_{\text {calcd }}=1.144 \mathrm{~mm}^{-1}, \mathrm{~F}(000)=12448$. 
A total of 105823 reflections were collected, of which 2202 were unique giving $\mathrm{R}$ int $=0.186$. Final $\mathbf{R}_{1}\left(w \mathrm{R}_{2}\right)=0.117$ (0.331) with $\mathrm{GoF}=1.663$. The final difference Fourier extreme were 1.577 and $-1.156 \mathrm{e}^{-3}$.

Crystal Data for MFM-170•0.09SO $2\left[\mathrm{Cu}_{2}\left(\mathrm{C}_{33} \mathrm{H}_{17} \mathrm{NO}_{8}\right)\left(\mathrm{SO}_{2}\right)_{0.09}\right]$; blue octahedron $(0.1 \times 0.1$ x $0.1 \mathrm{~mm})$. Cubic, Im$3 m, \mathrm{a}=33.5458(19) \AA, \mathrm{V}=37750(6) \AA, \mathrm{Z}=24, \rho_{\text {calcd }}=0.727 \mathrm{~g} \mathrm{~cm}^{-1} \cdot \mu_{\text {calcd }}=0.890 \mathrm{~mm}^{-1}, \mathrm{~F}(000)=8324$. A total of 73416 reflections were collected, of which 1471 were unique giving $\mathrm{R}$ int $=0.173$. Final $\mathrm{R}_{1}\left(w \mathrm{R}_{2}\right)=0.0411(0.092)$ with $\mathrm{GoF}=1.083$. The final difference Fourier extreme were 0.517 and $-0.474 \mathrm{e}^{-3}$.

Crystal Data for MFM-170· $\mathrm{H}_{2} \mathrm{O}\left[\mathrm{Cu}_{2}\left(\mathrm{C}_{33} \mathrm{H}_{17} \mathrm{NO}_{8}\right)\left(\mathrm{H}_{2} \mathrm{O}\right)_{0.50}\right]$; blue octahedron $(0.1 \times 0.1 \times 0.1 \mathrm{~mm})$. Cubic, Im-3m, $\mathrm{a}=33.4562(16) \AA, \mathrm{V}=37448(5) \AA, \mathrm{Z}=24, \rho_{\text {calcd }}=0.736 \mathrm{~g} \mathrm{~cm}^{-1} \cdot \mu_{\text {calcd }}=0.895 \mathrm{~mm}^{-1}, \mathrm{~F}(000)=8376$. A total of 110623 reflections were collected, of which 2211 were unique giving $\mathrm{R}$ int $=0.0699$. Final $\mathrm{R}_{1}\left(w \mathrm{R}_{2}\right)=0.0565(0.1799)$ with $\mathrm{GoF}=1.124$. The final difference Fourier extreme were 0.702 and $-0.458 \mathrm{e}^{-3}$.

Crystal Data for MFM-170· $\mathrm{H}_{2} \mathrm{O} \cdot 3.27 \mathrm{SO}_{2}\left[\mathrm{Cu}_{2}\left(\mathrm{C}_{33} \mathrm{H}_{17} \mathrm{NO}_{8}\right)\left(\mathrm{H}_{2} \mathrm{O}\right)_{0.79}\right]\left(\mathrm{SO}_{2}\right)_{3.27}$; blue octahedron $(0.1 \times 0.1 \times 0.1$ mm). Cubic, Im-3m, a =33.610(4)) $\AA, \mathrm{V}=37968(12) \AA^{3}, \mathrm{Z}=24, \rho_{\text {calcd }}=0.951 \mathrm{~g} \mathrm{~cm}^{-1} \mu_{\text {calcd }}=1.039 \mathrm{~mm}^{-1}, \mathrm{~F}(000)=$ 10957. A total of 84668 reflections were collected, of which 1720 were unique giving $\mathbf{R}$ int $=0.078$. Final $\mathbf{R}_{1}\left(w \mathbf{R}_{2}\right)$ $=0.0947(0.3006)$ with $\mathrm{GoF}=1.529$. The final difference Fourier extreme were 0.909 and $-0.618 \mathrm{e}^{-3}$.

A more detailed description of single crystal X-ray diffraction data can be found in the supplementary information.

Gas adsorption isotherms and breakthrough experiment: Measurements of $\mathrm{SO}_{2}$ adsorption isotherms $(0-1$ bar) were performed using a Xemis gravimetric adsorption apparatus (Hiden Isochema, Warrington, UK) equipped with a clean ultrahigh vacuum system. The pressure in the system is accurately regulated by mass flow controllers. Research grade $\mathrm{SO}_{2}$ and $\mathrm{He}$ were purchased from AIRLIQUIDE or BOC and used as received. In a typical gas adsorption experiment, $70-100 \mathrm{mg}$ of MFM-170 $\cdot \mathrm{H}_{2} \mathrm{O} \cdot$ solv was loaded into the Xemis, and degassed at $423 \mathrm{~K}$ and high dynamic vacuum (10 $10^{-10}$ bar) for 1 day to give desolvated MFM-170.

Breakthrough experiments were carried out in a $7 \mathrm{~mm}$ diameter fixed-bed tube of $120 \mathrm{~mm}$ length packed with $1.5 \mathrm{~g}$ of MFM-170 powder (particle size $<5$ microns). The total volume of the bed was $c a .5 \mathrm{~cm}^{3}$. The sample was heated at $423 \mathrm{~K}$ under a flow of He for 2 days for complete activation. The fixed-bed was then cooled to room temperature $(298 \mathrm{~K})$ using a temperature programmed water bath and the breakthrough experiment was performed with streams of $\mathrm{SO}_{2}(0.5 \%$ diluted in $\mathrm{He})$ and $\mathrm{CO}_{2}$ at atmospheric pressure and room temperature. The flow rate of the entering gas mixture was maintained at $47 \mathrm{~mL} \mathrm{~min}^{-1}$, and the gas concentration, $C$, of $\mathrm{SO}_{2}$ and $\mathrm{CO}_{2}$ at the outlet determined by mass spectrometry and compared with the corresponding inlet concentration $C_{0}$, where $C / C_{0}=1$ indicates complete breakthrough. A more detailed description is given in SI.

Supplementary Information is available in the online version of the paper.

Acknowledgements. We thank EPSRC (EP/I011870), ERC (AdG 742041), the Royal Society and University of Manchester for funding. We are especially grateful to Diamond Light Source (DLS), Advanced Light Source, Oak Ridge National Laboratory and STFC/ISIS Neutron Facility for access to the Beamlines B22/I11, 11.3.1, VISION and TOSCA, respectively. We thank Mark Kibble for the help at TOSCA beamline. The computing resources were made available through the VirtuES and the ICE-MAN projects, funded by Laboratory Directed Research and Development program at ORNL. This research used 
resources of the Advanced Light Source, which is a DOE Office of Science User Facility under contract no. DE-AC02-05CH11231. JL, XZ thank China Scholarship Council for funding.

Author Contributions. GLS, JEE: synthesis and characterisation of MOF samples, measurements of adsorption isotherms. GLS, XH: measurements and analysis of the breakthrough data. GLS, XZ, SPA, LJM, SJTL, SY: collection and analysis of synchrotron single crystal X-ray diffraction data. GLS, HGWG, YC, SR, AJRC: collection and analysis of neutron scattering data. GLS, SJD and CCT: collection and analysis of long duration synchrotron X-ray diffraction data. GLS, JL, NMJ, MDF, GC, TLE: collection and analysis of synchrotron IR data. SY and MS: overall design and direction of project. GLS, SY and MS: preparation of the manuscript with help from all authors.

Author Information. The crystal structures are available free of charge from the Cambridge Crystallographic Data Centre under reference number CCDC-1538125-6, 1538129, 1853512-4. Reprints and permissions information is available at www.nature.com/reprints. The authors declare no competing financial interests. Correspondence and requests for materials should be addressed to S.Y. (Sihai.Yang@manchester.ac.uk) and M.S. (M.Schroder@manchester.ac.uk).

Competing financial interests. The authors declare no competing financial interests.

Data availability. All relevant data are available from the authors, and/or are included with the manuscript. 
a)<smiles>O=C(O)c1ccc(-c2ccc(-c3ccc(-c4cc(C(=O)O)cc(C(=O)O)c4)cc3)cc2)cc1</smiles>

c)

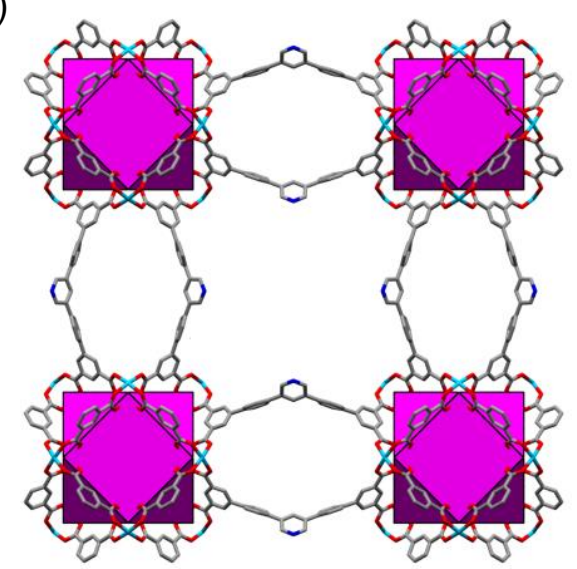

b)

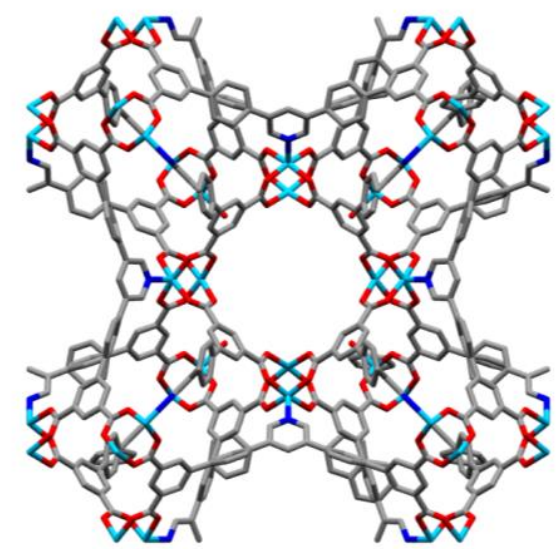

d)

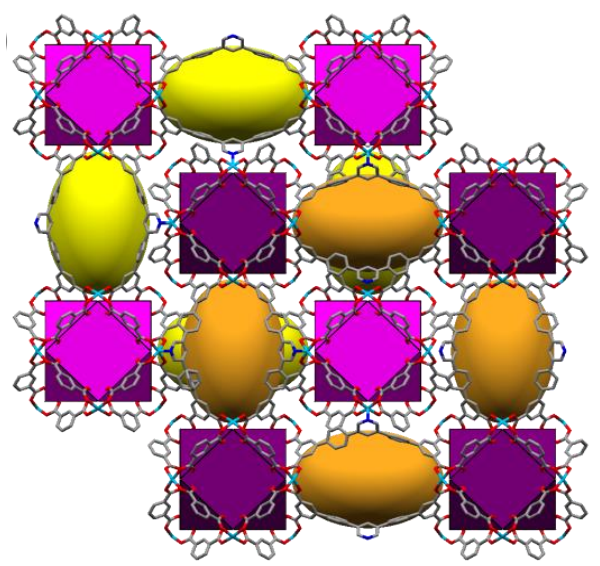

e)

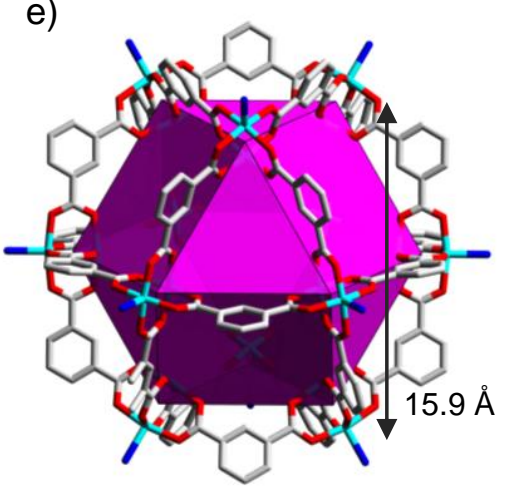

Cage $\boldsymbol{A}$

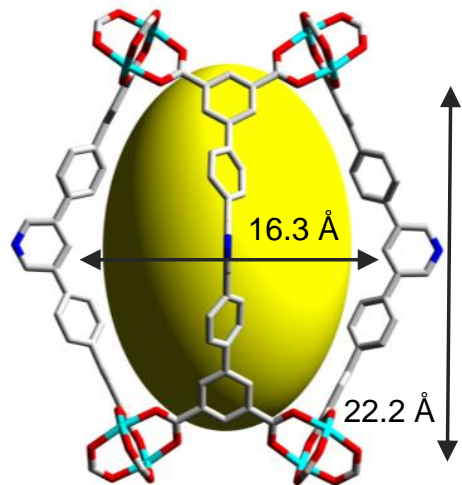

Cage $\boldsymbol{B}$

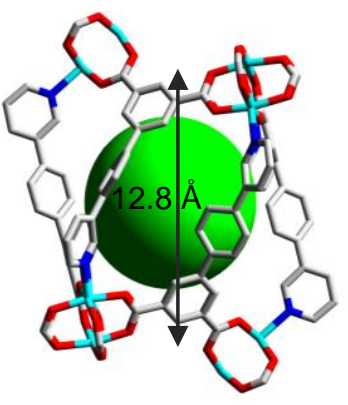

Cage $\boldsymbol{C}$

Fig. 1: Structure of MFM-170 solved from single crystal X-ray data. Views of a) structure of $\mathrm{H}_{4} \mathrm{~L}$; b) the unit cell of MFM-170; c) the simplified structure showing the 'smaller' net of MFM-170; d) full structure resulting from connection of the two smaller nets; e) metal-ligand Cages $A, B$ and $C$, observed in MFM-170. 
Table 1: Comparison of data for $\mathrm{SO}_{2}$ adsorbents.

\begin{tabular}{|c|c|c|c|c|}
\hline Material & $\begin{array}{l}\text { BET Surface } \\
\text { Area }\left(\mathbf{m}^{2} \mathbf{g}^{-1}\right)\end{array}$ & $\begin{array}{l}\text { Open Metal } \\
\text { Site }\end{array}$ & $\begin{array}{l}1 \mathrm{Bar} \mathrm{SO}_{2} \\
\text { Uptake at } \\
298 \mathrm{~K}(\mathrm{mmol} \\
\left.\mathrm{g}^{-1}\right)\end{array}$ & Ref \\
\hline MFM-170 & 2,408 & $\mathrm{Y}$ & 17.5 & This work \\
\hline MFM-170- $\mathrm{H}_{2} \mathrm{O}$ & 2,003 & $\mathrm{~N}$ & 13.0 & This work \\
\hline MFM-601 & 3644 & $\mathrm{~N}$ & 12.3 & 15 \\
\hline SIFSIX-1-Cu & 1,337 & $\mathrm{~N}$ & 11.0 & 16 \\
\hline$\left[\mathrm{Zn}_{2}\left(\mathrm{~L}_{1}\right)_{2}(\right.$ bipy $\left.)\right]$ & $275^{\mathrm{a}}$ & $\mathrm{N}$ & $10.9^{\mathrm{b}}$ & 17 \\
\hline MFM-202a & 2,220 & $\mathrm{~N}$ & $10.2^{\mathrm{c}}$ & 18 \\
\hline $\mathrm{Ni}(\mathrm{bdc})(\mathrm{ted})_{0.5}$ & 1,783 & $\mathrm{~N}$ & 10.0 & 19 \\
\hline Mg-MOF-74 & 1,475 & $\mathrm{Y}$ & 8.6 & 19 \\
\hline MFM-300(In) & 1,071 & $\mathrm{~N}$ & 8.3 & 20 \\
\hline MFM-305 & 799 & $\mathrm{~N}$ & 7.0 & 21 \\
\hline SIFSIX-2-Cu-i & 735 & $\mathrm{~N}$ & 6.9 & 16 \\
\hline PI-COF-m & 1,003 & $\mathrm{n} / \mathrm{a}$ & 6.5 & 22 \\
\hline SIFSIX-2-Cu & 3,140 & $\mathrm{~N}$ & 6.5 & 16 \\
\hline$\left[\mathrm{Zn}_{2}\left(\mathrm{~L}_{1}\right)_{2}(\mathrm{bpe})\right]$ & $379^{\mathrm{a}}$ & $\mathrm{N}$ & $6.4^{\mathrm{b}}$ & 17 \\
\hline PI-COF-m10 & 831 & $\mathrm{n} / \mathrm{a}$ & 6.3 & 22 \\
\hline PI-COF-m20 & 548 & $\mathrm{n} / \mathrm{a}$ & 5.6 & 22 \\
\hline PI-COF-m40 & 279 & $\mathrm{n} / \mathrm{a}$ & 5.5 & 22 \\
\hline MFM-305- $\mathrm{CH}_{3}$ & 256 & $\mathrm{~N}$ & 5.2 & 21 \\
\hline MFM-600 & 2281 & $\mathrm{~N}$ & 5.0 & 15 \\
\hline PI-COF-m60 & 93 & $\mathrm{n} / \mathrm{a}$ & 4.7 & 22 \\
\hline $\mathrm{Zn}(\mathrm{bdc})(\mathrm{ted})_{0.5}$ & 1,888 & $\mathrm{~N}$ & 4.4 & 19 \\
\hline KAUST-8 & 250 & $\mathrm{Y}$ & $\sim 2.9^{\mathrm{d}}$ & 25 \\
\hline SIFSIX-3-Ni & 223 & $\mathrm{~N}$ & 2.7 & 16 \\
\hline KAUST-7 & 280 & $\mathrm{~N}$ & $\sim 2.6^{\mathrm{d}}$ & 25 \\
\hline Prussian Blue (CoCo) & 712 & $\mathrm{~N}$ & 2.5 & 23 \\
\hline$\left[\mathrm{Zn}_{4}\left(\mu_{4}-\mathrm{O}\right)\left(\mathrm{L}_{1}\right)_{3}\right]$ & $299^{\mathrm{a}}$ & $\mathrm{N}$ & $2.2^{\mathrm{b}}$ & 17 \\
\hline FMOF-2 & 378 & $\mathrm{Y}$ & 2.2 & 24 \\
\hline SIFSIX-3-Zn & 250 & $\mathrm{~N}$ & 2.1 & 16 \\
\hline
\end{tabular}

a. DFT-calculated surface area ${ }^{\text {b. }} 293 \mathrm{~K}^{\text {c. }}$ MFM-202a exhibits reversible $\mathrm{SO}_{2}$ adsorption at 273-303K, but undergoes an irreversible phase change at lower temperatures. ${ }^{\mathrm{d} .}$ estimated from isotherm 


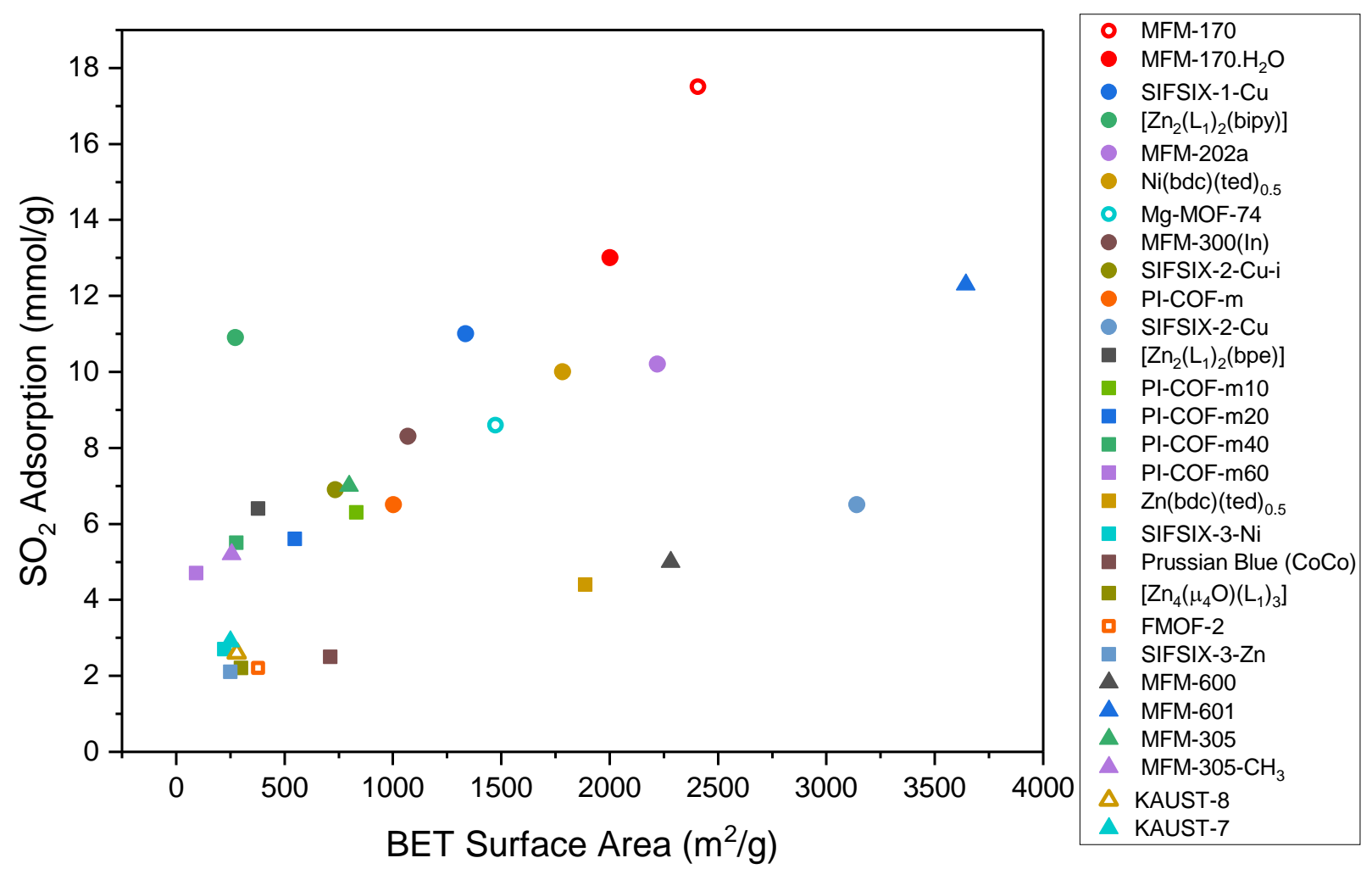

Fig. 2: Comparison of $\mathrm{SO}_{2}$ uptakes of reported MOFs and COFs at 1.0 bar and $298 \mathrm{~K}$. Plot of $\mathrm{SO}_{2}$ adsorption $(1.0 \mathrm{bar}, 298 \mathrm{~K})$ against BET surface area. Open symbols denote the presence of open metal sites in the MOF structure. 
a)

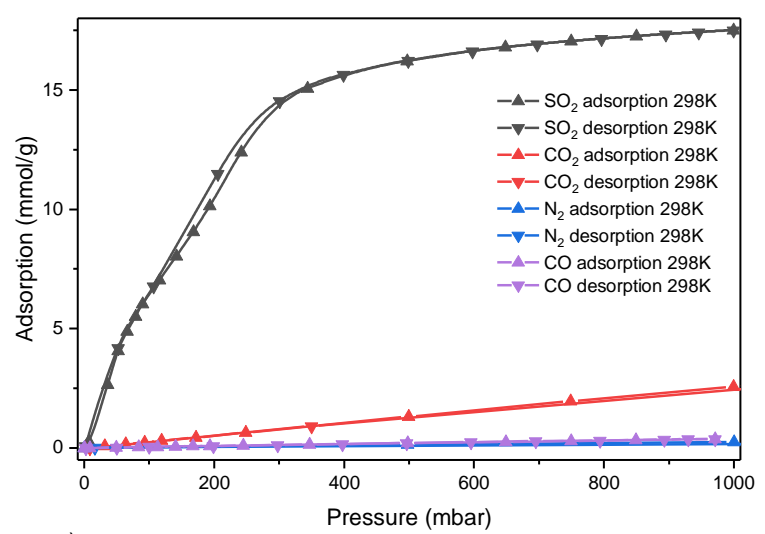

c)

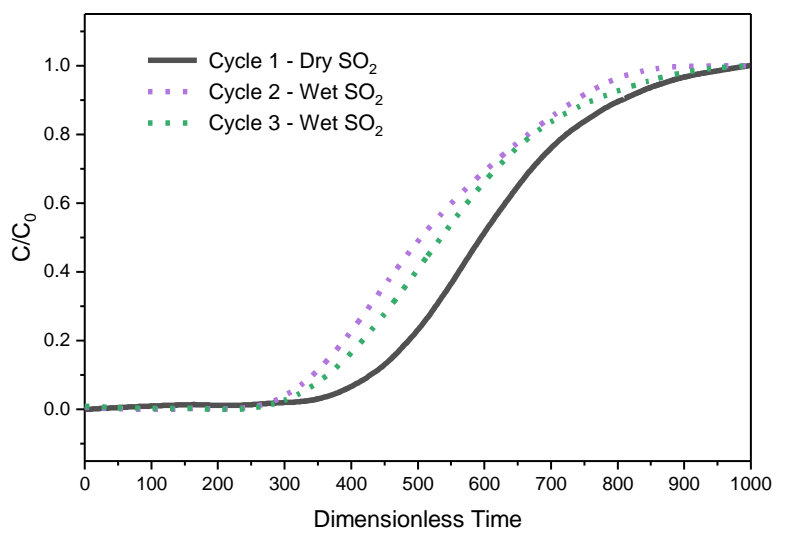

b)
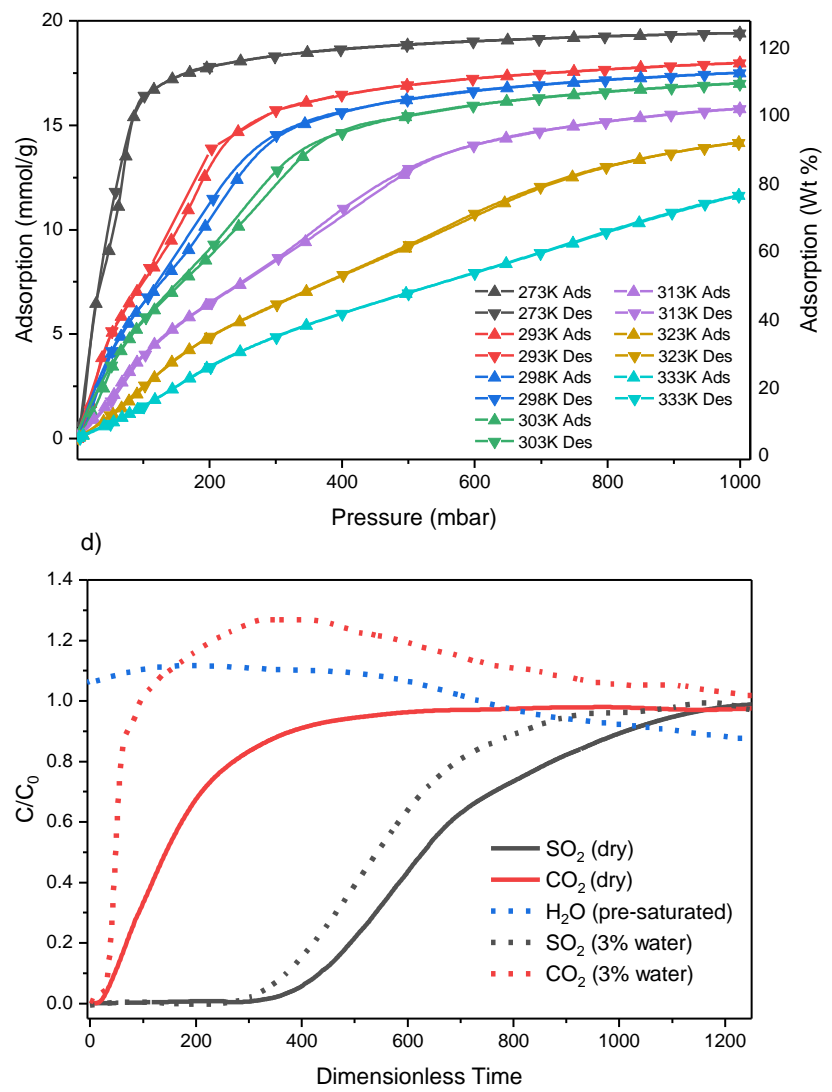

Fig. 3: Gas sorption properties of MFM-170. a) adsorption and desorption isotherms for MFM-170 at $298 \mathrm{~K}$ up to 1 bar for $\mathrm{SO}_{2}$ (black), $\mathrm{CO}_{2}$ (red), $\mathrm{N}_{2}$ (blue) and $\mathrm{CO}$ (purple); b) $\mathrm{SO}_{2}$ adsorption and desorption isotherms for MFM170 at $273-333 \mathrm{~K}$ up to 1 bar. Wt $\%$ is in terms of $\mathrm{SO}_{2}(\mathrm{~g}) / \mathrm{MOF}(\mathrm{g})$. c) Breakthrough curves for $\mathrm{SO}_{2}$ at $298 \mathrm{~K}$ under dry (solid line) and humid (dashed lines) conditions. The consistency in the retention time for $\mathrm{SO}_{2}$ under humid conditions confirms the high stability of MFM-170. Dry conditions: $99.75 \% \mathrm{He}, 2500 \mathrm{ppm} \mathrm{SO}{ }_{2}$; Wet Conditions: $98.25 \% \mathrm{He}, 1.5 \% \mathrm{H}_{2} \mathrm{O}, 2500 \mathrm{ppm} \mathrm{\textrm {SO } _ { 2 }}$. Flow rate $26 \mathrm{~mL} \mathrm{~min}^{-1}$. d) Comparison of the binary $\mathrm{SO}_{2} / \mathrm{CO}_{2}$ dynamic separations at $298 \mathrm{~K}$ under dry (solid line) and humid (dashed line) conditions. The dry sample was first activated under a flow of $\mathrm{He}$ at $423 \mathrm{~K}$ and the subsequent gas mixture composition was $84.75 \% \mathrm{He}, 15 \% \mathrm{CO}_{2}$ and $2500 \mathrm{ppm}$ $\mathrm{SO}_{2}$ at a total flow rate of $26 \mathrm{~mL} \mathrm{~min}^{-1}$. For experiments under humid conditions, the bed was first exposed to a flow of $3 \% \mathrm{H}_{2} \mathrm{O}$ in $\mathrm{He}$ until breakthrough of water (not shown). The subsequent gas mixture composition was $\sim 81.6 \% \mathrm{He}$, $18 \% \mathrm{CO}_{2}$ and $4050 \mathrm{ppm} \mathrm{SO}_{2}$ with a total flow rate of $16 \mathrm{~mL} \mathrm{~min}^{-1}$. Dimensionless time, $\tau$, is equal to $t u / \varepsilon L$, where $t$ is the actual breakthrough time, $u$ is the gas velocity, $\varepsilon$ is the fractional porosity and $L$ is the length of the fixed bed. See Supplementary Information for details. 
a)

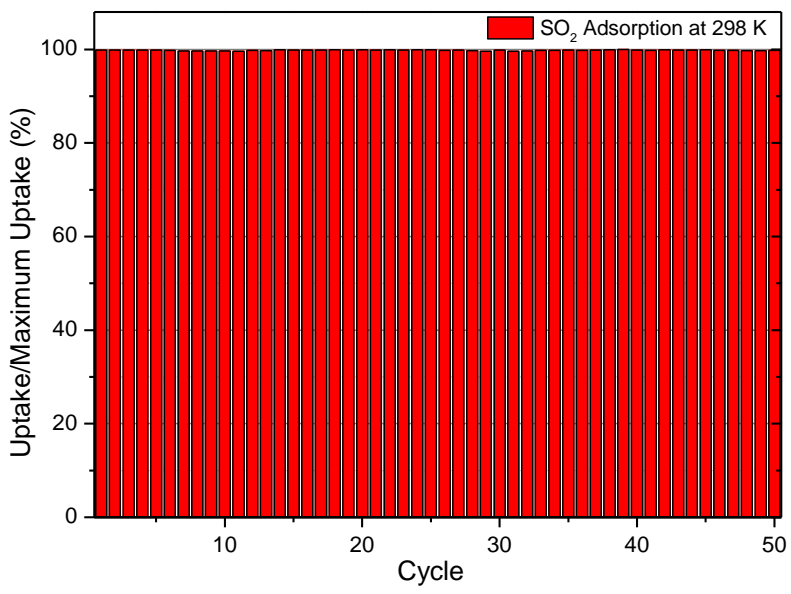

b)

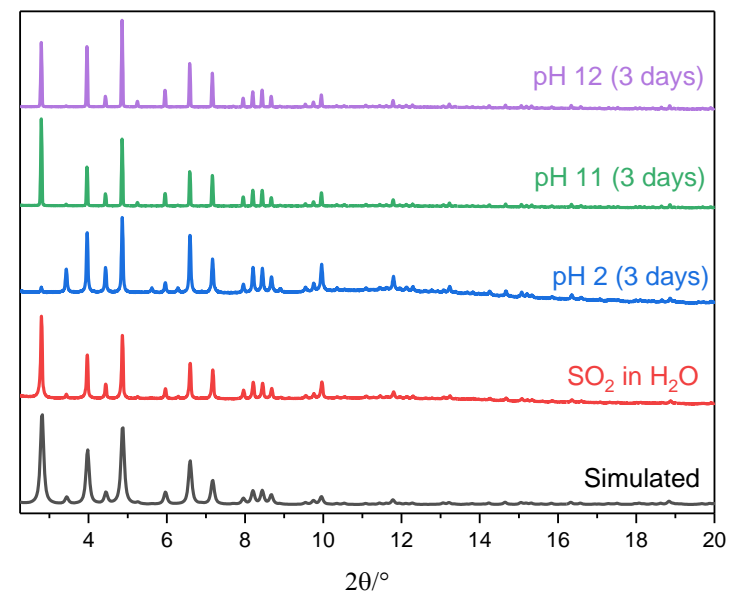

Fig. 4. Chemical stability tests for MFM-170. a) 50 adsorption-desorption cycles for $\mathrm{SO}_{2}$ in $\mathrm{MFM}-170$ at $298 \mathrm{~K}$. No loss of uptake capacity is observed. b) PXRD analysis of MFM-170 exposed to various external conditions. Changes of intensities of Bragg peaks correspond to the inclusion of guest species in the pores of MFM-170. Pawley refinements are shown in the Supplementary Information. 
a)

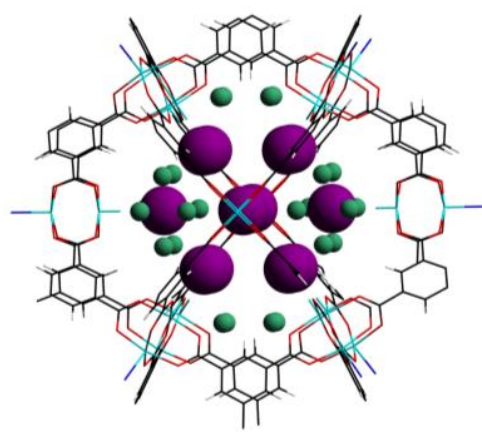

Cage $\boldsymbol{A}$

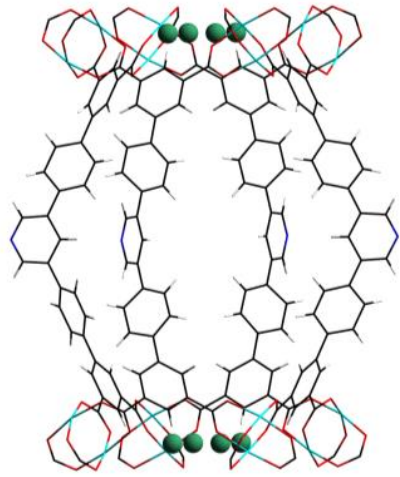

Cage $\boldsymbol{B}$

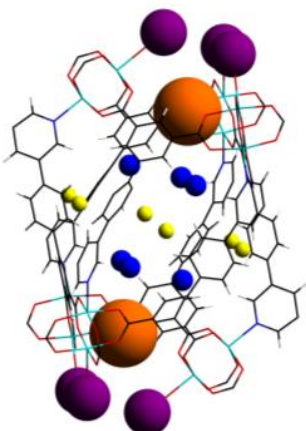

Cage $\boldsymbol{C}$
$\mathrm{SO}_{2}$ Site (occ.)

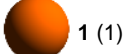

2 (0.67)

$3(0.47)$

- $4(0.32)$

- $5(0.26)$

- $6(0.23)$

b)
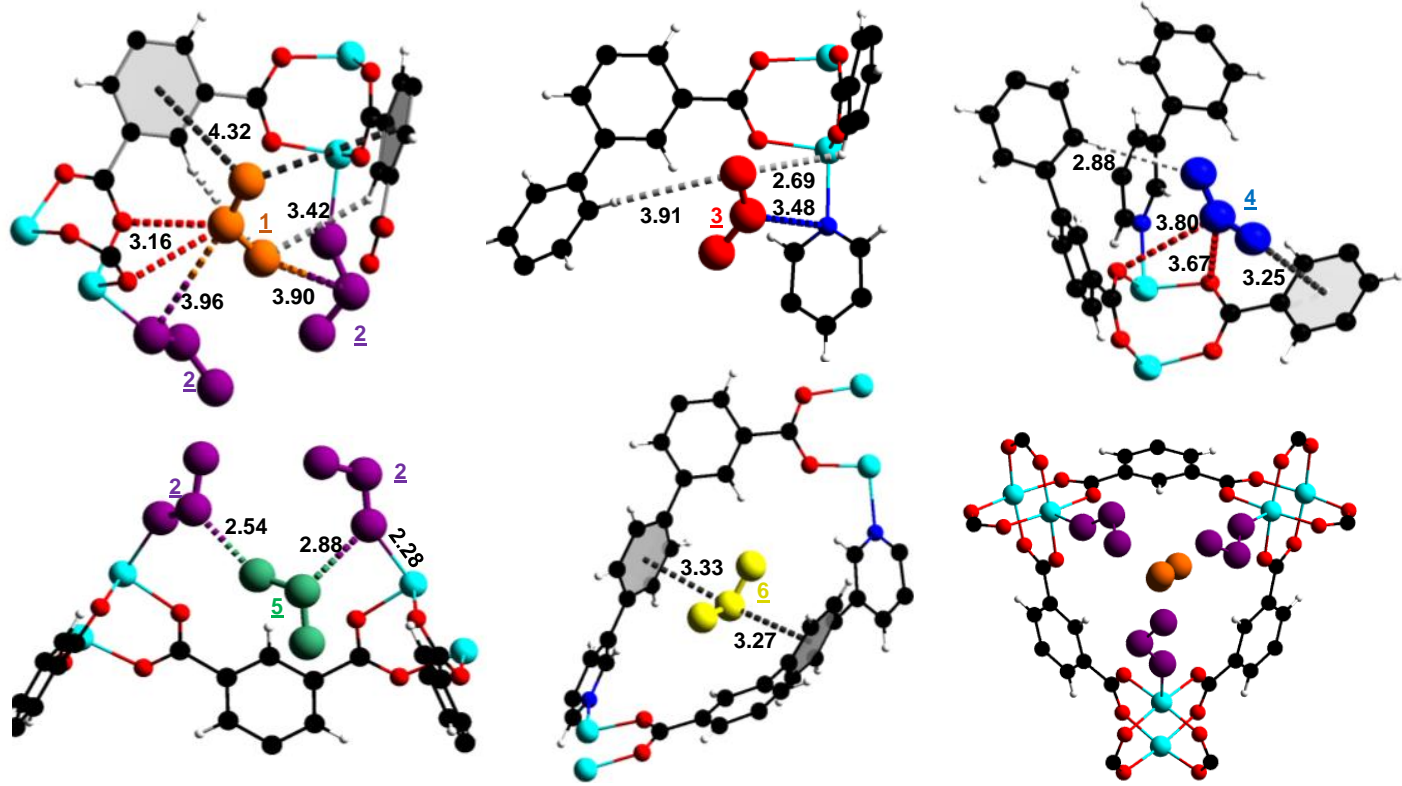

c)

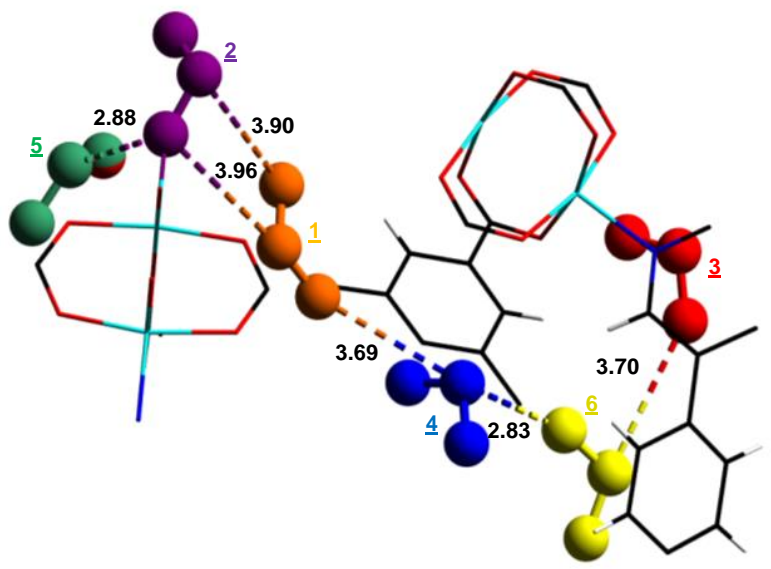

Fig. 5: Positions of $\mathrm{SO}_{2}$ molecules located within the pores of $\mathrm{MFM}-170 \cdot 5.46 \mathrm{SO}_{2}$ from in situ single crystal XRD. a) Packing of $\mathrm{SO}_{2}$ with in cages $\boldsymbol{A}, \boldsymbol{B}$ and $\boldsymbol{C}$. No ordered $\mathrm{SO}_{2}$ was found in cage $\boldsymbol{B}$. Size of the coloured balls depicting sites 1-6 are proportional to their occupancy. Site $\mathbf{3}$ is found in a crevice between two perpendicular cage $\boldsymbol{B}$ and are therefore not shown in the cages. b) Site (colour, occupancy): 1 (orange, 1.00); 2 (purple, 0.670); 3 (red, 0.468); 4 (blue 0.316); 5 (green, 0.262); and 6 (yellow, 0.233). c) Intermolecular interactions between adsorbed $\mathrm{SO}_{2}$ molecules. $\mathrm{SO}_{2}$ molecules have been magnified slightly for clarity. Distances are in $\AA$. 

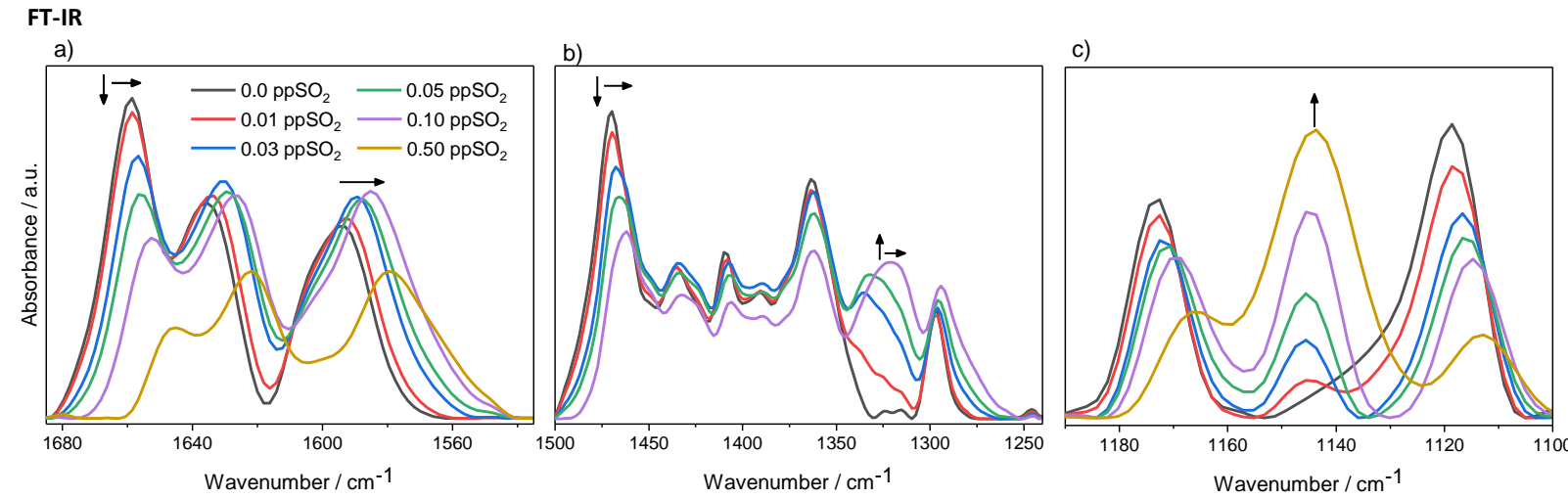

INS

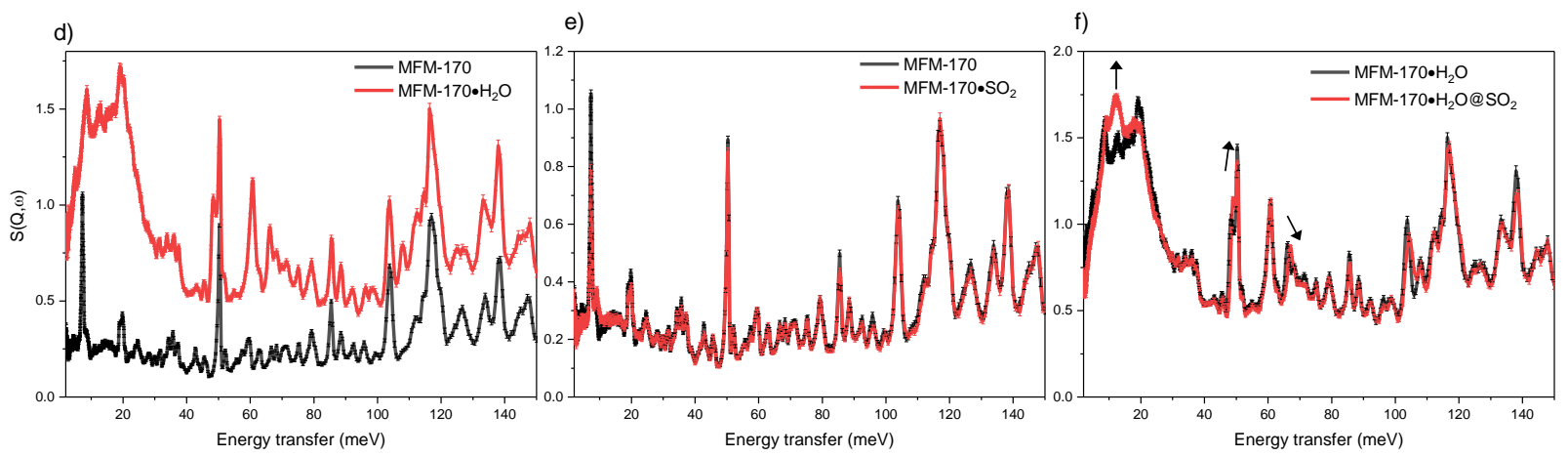

Fig 6. In situ vibrational spectra of MFM-170. a-c) FT-IR spectra of MFM-170 at various $\mathrm{SO}_{2}$ loadings up to 0.50 $\mathrm{ppSO}_{2}$. a) Redshift of carboxylate $v_{\text {as }}(\mathrm{COO})$ stretching mode at $1658 \mathrm{~cm}^{-1}$ and pyridine ring vibrational band $v(\mathrm{CC} / \mathrm{CN})$ at $1595 \mathrm{~cm}^{-1}$; b) Red shift of $v_{\mathrm{s}}(\mathrm{COO})$ stretching mode at $1470 \mathrm{~cm}^{-1}$ and the $v_{3}$ asymmetric stretch of adsorbed $\mathrm{SO}_{2} ; \mathrm{c}$ ) growth of a new band at $1143 \mathrm{~cm}^{-1}$ assigned to the $v_{1}$ symmetric stretch of adsorbed $\mathrm{SO}_{2}$. All FT-IR spectra were collected at $1.0 \mathrm{bar}$, using $\mathrm{N}_{2}$ as a balancing gas. The fundamental $v_{3}$ antisymmetric stretch of gas phase $\mathrm{SO}_{2}$ at $1361 \mathrm{~cm}^{-1}$ saturates at low partial pressures in this experiment, and therefore the region of $1400-1300 \mathrm{~cm}^{-1} \mathrm{was}$ only monitored up to $0.10 \mathrm{ppSO}_{2}$; d-f) INS spectra of MFM-170: d) Activated MFM-170 and MFM-170 $\cdot \mathrm{H}_{2} \mathrm{O}$. Additional peaks in MFM-170 $\mathrm{H}_{2} \mathrm{O}$ are attributed to vibrational modes of water molecules; e) Activated MFM-170 and MFM-170@ $\mathrm{SO}_{2}$. Minimal difference is observed between the two spectra; f) MFM-170 $\cdot \mathrm{H}_{2} \mathrm{O}$ and MFM$170 \cdot \mathrm{H}_{2} \mathrm{O} @ \mathrm{SO}_{2}$. Shifts in water modes are observed indicating $\mathrm{H}_{2} \mathrm{O} \cdots \mathrm{SO}_{2}$ interactions. 